\title{
Pore-fluid-dependent controls of matrix and bulk thermal conductivity of mineralogically heterogeneous sandstones
}

\author{
Marion Kämmlein * (i) and Harald Stollhofen
}

\author{
*Correspondence: \\ marion.kaemmlein@fau.de \\ GeoZentrum Nordbayern, \\ Friedrich-Alexander- \\ University Erlangen-Nürnberg \\ (FAU), Schlossgarten 5, \\ 91054 Erlangen, Germany
}

\begin{abstract}
For a variety of geothermal engineering applications, the only indirectly determinable matrix thermal conductivity $\left(\lambda_{m}\right)$ is frequently used to convert the measured bulk rock thermal conductivity $\left(\lambda_{b}\right)$ of air-saturated sandstones to water-saturated conditions. However, the necessary assumption that the absolute value of $\lambda_{m}$ remains constant irrespective of the pore fluid present turns out to be not valid in practice and the explicit control factors on $\lambda_{\mathrm{m}}$ have not been demonstrated yet for different pore fluids. A pore fluid-controlled change in the $\lambda_{m}$ value also questions the transferability of empirical proxy models for the estimation of water-saturated $\lambda_{b}$ when they were calibrated on air-saturated samples. This study applies a multiple regression analysis to quantitative mineralogical composition data and porosity $(\Phi)$ to identify the controls of the $\lambda_{m}$ for different types of pore fluids (water- vs. air-saturation). In addition, the differences in the calculated $\lambda_{m}$ values resulting from different calculation methods or input data (theoretical geometric mean model or mineralogical composition data) are examined. We further test the suitability of different sandstone properties as potential proxies for the estimation of the $\lambda_{\mathrm{b}}$, with respect to the pore fluid type. Differences in the absolute value of $\lambda_{m}$ of sandstones from different measurement conditions (air- or water-saturated) are most probably related to the formation of authigenic kaolinite in the pore space, originating from the alteration of alkali feldspar. In addition, the thermal properties of the rock matrix are mainly controlled by the volume fractions of the high thermally conductive mineral fractions quartz and dolomite. Empirical models that have solely $\Phi$ or P-wave velocity $\left(v_{p}\right)$ as variables are not suitable for the prediction of water-saturated $\lambda_{b}$ of sandstones. Instead, quantitative mineralogical data of high thermally conductive mineral phases such as quartz and dolomite have to be included. The easily measureable $v_{p}$ is proposed as a promising proxy for both pore fluid types tested: combined with the total quartz volume/porosity ratio for air-saturated sandstones, and combined with the quartz plus dolomite volume fractions for water-saturated sandstones.
\end{abstract}

Keywords: Matrix thermal conductivity, Bulk thermal conductivity, Pore fluid, Sandstone, Mineralogical composition, Anisotropy 


\section{Introduction \\ Background}

The thermal conductivity of rocks is a key physical rock parameter that is required for the estimation of crustal heat flow in geodynamic studies (e.g., Chapman and Rybach 1985), for modeling thermal histories and organic maturation in sedimentary basins (e.g., Blackwell and Steele 1989) and for a variety of engineering applications such as the suitability of underground nuclear waste repositories (e.g., Horseman and McEwen 1996), laser spallation drilling of rocks (e.g., Xu et al. 2004), utilization of geothermal energy, and underground energy storage. Particularly the ongoing exploitation of hydrothermal geothermal systems led to a high demand for accurate thermophysical data in projected target areas. The bulk rock thermal conductivity $\left(\lambda_{\mathrm{b}}\right)$ is in this context a key parameter for reasonable geothermal models, as it quantifies the ability of a material to conduct heat (Somerton 1992).

Although new techniques such as the optical scanning method (Popov et al. 1999) allow rapid measurements of $\lambda_{\mathrm{b}}$, the generation of statistically reliable datasets covering large stratigraphic sections is very time-consuming and might require multi-year studies (c.f., Clauser et al. 2007, 2009; Fuchs and Föster 2010; Bär 2012; Jorand et al. 2015; Fuchs and Balling 2016). Especially in the case of sandstones, the alternative use of textbookderived mean values for thermal modeling is not sufficient for accurate temperature predictions. Sandstones can have a very large range in $\lambda_{\mathrm{b}}$ (e.g., Somerton 1992; Schön 2015), dependent on the variability of controlling rock parameters such as their mineralogical composition, porosity, textural features like detrital grain contacts, grain geometry, bedding, type of cementation, and the type of the pore fluid (e.g., Zimmerman 1989; Clauser and Huenges 1995; Sun et al. 2017).

\section{Existing and new empirical models for bulk thermal conductivity prediction}

A large number of empirical models for $\lambda_{\mathrm{b}}$ prediction of different rock types exists, based on other physical properties, such as porosity $(\Phi)$ (e.g., Sugawara and Yoshizawa 1961; Maqsood et al. 2004), bulk density (Anand et al. 1973), P-wave velocity $\left(v_{\mathrm{p}}\right)$ (e.g., Goss et al. 1975; Hartmann et al. 2005; Gegenhuber and Schön 2012), or mineralogical composition (e.g., Birch and Clark 1940; Horai and Baldridge 1972). The theoretical geometric mean model (Woodside and Messmer 1961a, b) often is applied to convert $\lambda_{\mathrm{b}}$ values measured of air-saturated sandstone samples to $\lambda_{\mathrm{b}}$ values considering water-saturated conditions (e.g., Aurangzeb and Maqsood 2007; Fuchs et al. 2013) as it is the only mixing law model which provides reliable results for porous rocks (e.g., Pribnow 1994; Fuchs et al. 2013). A significant uncertainty in applying the geometric mean model arises from the assumption that the type of the saturating pore fluid does not affect the key parameter matrix thermal conductivity $\left(\lambda_{\mathrm{m}}\right)$. This parameter represents the thermal properties of the solid rock constituents and cannot be measured directly. The values of $\lambda_{\mathrm{m}}$ should-in theory-remain the same, independent of whether they were calculated from $\lambda_{\mathrm{b}}$ measurements of dry or water-saturated rocks. However, several studies have shown that this assumption is incorrect and that the type of the pore fluid does affect the absolute $\lambda_{\mathrm{m}}$ value of porous rocks like sandstones (e.g., Fuchs et al. 2013; Albert et al. 2017). Moreover, 
differences in the $\lambda_{\mathrm{m}}$ values of porous rocks can be expected, if $\lambda_{\mathrm{m}}$ is calculated on the basis of different methods or input data, namely from mineralogical composition data (e.g., Horai and Baldridge 1972; Andrés et al. 2016) or directly from $\lambda_{\mathrm{b}}$ measurements. Also when $\lambda_{\mathrm{b}}$ is derived from well data (e.g., Goutorbe et al. 2006; Fuchs and Förster 2014; Gasior and Przelaskowska 2014), any variation in the absolute value of $\lambda_{\mathrm{m}}$ would be relevant with respect to the database used in order to calibrate models. However, the explicit control factors on pore-fluid-dependent and methodologically dependent differences of the resulting $\lambda_{\mathrm{m}}$ value of a sandstone sample have not been demonstrated yet. This is mostly related to the scarcity of quantitative mineralogical composition data, which are needed to identify the specific impact of single mineral phases on $\lambda_{\mathrm{m}}$. Studies that examined the methodological aspect of the $\lambda_{\mathrm{m}}$ determination indicate a fluctuation of the absolute $\lambda_{\mathrm{m}}$ value when different types of fluid are present in the pore space, but only included a few measurements of sandstones (e.g., Clauser and Huenges 1995; Jorand et al. 2015).

The fact that the type of pore fluid present in sandstones has an impact on the $\lambda_{\mathrm{m}}$ also affects the application of empirical models that use other rock properties as potential proxies for sandstone $\lambda_{\mathrm{b}}$. Models calibrated on dry samples are not readily transferable to water-saturated conditions. The pore-fluid-dependent thermal properties of the rock matrix in sandstones also play a role in view of the high variability in the mineralogical composition of this rock type. For example, empirical models for $\lambda_{\mathrm{b}}$ calibrated on clean sandstones are not necessarily transferable to compositionally immature sandstones, composed of many different mineral phases.

Therefore, the application of an empirical model for $\lambda_{\mathrm{b}}$ of sandstones has to be critically assessed, especially with regard to the following aspects:

- Is the model transferable to water-saturated (in situ) conditions, when it is calibrated on air-saturated rock samples?

- Is the model also valid for mineralogically heterogeneous sandstones, when it is calibrated on clean sandstones (e.g., Brigaud and Vasseur 1989; Pimienta et al. 2014) or other rock types?

Consequently, a systematic study for determination of the pore-fluid-dependent suitability of individual rock parameters for $\lambda_{\mathrm{b}}$ prediction of sandstones with high mineralogical variability is lacking. Therefore this study pursues three research objectives:

- The identification of the control factors on $\lambda_{\mathrm{m}}$ of sandstones with respect to the type of the pore fluid (air vs. water saturation). This includes the quantification of the individual impact of specific mineral phases and porosity on $\lambda_{\mathrm{m}}$.

- The examination of differences resulting from the calculation of the parameter $\lambda_{\mathrm{m}}$ based on direct measurement of $\lambda_{\mathrm{b}}$ or indirectly, from mineralogical composition data.

- A pore fluid-related suitability test of $\Phi, v_{\mathrm{p}}$, and the quartz volume fraction, which are potential proxies for the estimation of the bulk rock thermal conductivity of sandstones: air vs. water saturation. 
In order to reduce anisotropy-related errors, we further determine the influence of anisotropy effects on $v_{\mathrm{p}}$ and $\lambda_{\mathrm{b}}$ measurements. This aspect should be considered during the development of empirical models based on the correlation of different rock properties (e.g., Robertson 1988; Pribnow 1994), but is not always included.

We further present new empirical models for the prediction of water-saturated $\lambda_{\mathrm{b}}$ values of sandstones, which are calibrated by their mineralogical composition and do not require $\lambda_{\mathrm{m}}$ as an input parameter. Water-saturated measurement conditions seem better comparable to real in situ subsurface conditions and are therefore rated as more reliable.

\section{Study area and methods}

\section{Geological setting}

The sampled area is located within the Franconian Basin of SE Germany (Freudenberger and Schwerd 1996), which is a subbasin of the Central European Basin System (Littke et al. 2008). The area comprises a Permo-Triassic sedimentary succession (Fig. 1) up to $1700 \mathrm{~m}$ thick. The Buntsandstein sections record terrestrial environments and are made up of interbedded sand-, clay-, and siltstones. The Lower and Upper Muschelkalk primarily consist of marine fossiliferous limestones, mudstones, and marlstones with marine evaporitic lithologies focussed to the Middle Muschelkalk. The Keuper involves essentially non-marine clay-rich sandstones, claystones, siltstones, dolomite rocks, and gypsum rocks (Table 1 ).

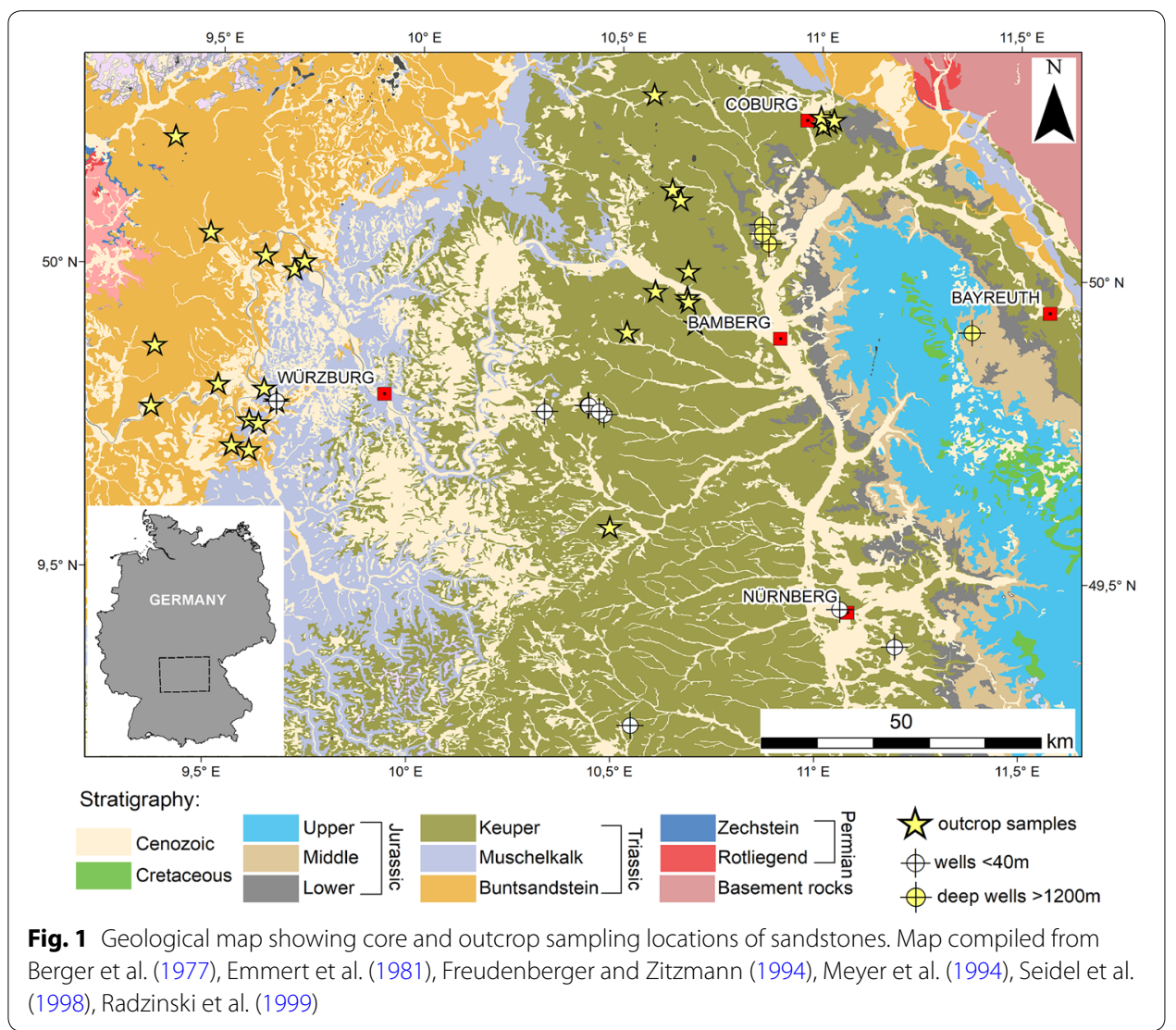


Table 1 Stratigraphic chart and main lithologies of the Permo-Triassic sedimentary succession in SE Germany (STC 2016)

\begin{tabular}{|c|c|c|c|c|}
\hline Period & Group & & Formation (Folge) & Main lithology \\
\hline \multirow[t]{21}{*}{ TRIASSIC } & Keuper & $U$ & Exter-Fm. & Sst, Clst \\
\hline & & M & Trossingen-Fm. & Clst \\
\hline & & & Löwenstein-Fm. & Sst, Clst \\
\hline & & & $\begin{array}{l}\text { Mainhardt-Fm.b)/ } \\
\text { Hassberge-Fm. }\end{array}$ & Clst, Gyp, Anhy/Sst \\
\hline & & & Steigerwald-Fm. & Clst \\
\hline & & & Stuttgart-Fm. & Sst, Clst \\
\hline & & L & $\begin{array}{l}\text { Grabfeld-Fm./Benk- } \\
\text { Fm. }\end{array}$ & Clst, Gyp, Anhy/Sst \\
\hline & & & $\begin{array}{l}\text { Erfurt-Fm./Grafen- } \\
\text { wöhr-Fm. }\end{array}$ & Clst, Dol/Sst \\
\hline & Muschelkalk & $U$ & Meißner-Fm. & Ls, mrlst, Clst \\
\hline & & & Trochitenkalk-Fm. & Ls, Clst \\
\hline & & M & Diemel-Fm. & Dol, mrlst \\
\hline & & & Heilbronn-Fm. & Anhy, Gyp \\
\hline & & & Karlstadt-Fm. & Dol, mrlst \\
\hline & & L & Jena-Fm. & mrlst, Clst, Ls \\
\hline & Buntsandstein & $U$ & Röt-Fm. & Sst, mrlst \\
\hline & & M & Solling-Fm. & Sst, Clst \\
\hline & & & Hardegsen-Fm. & Sst, Clst \\
\hline & & & Detfurth-Fm. & Sst, Clst \\
\hline & & & Volpriehausen-Fm. & Sst, Clst \\
\hline & & L & Bernburg-Fm. & Sst, Clst \\
\hline & & & Calvörde-Fm. & Sst, Clst \\
\hline \multirow[t]{3}{*}{ PERMIAN } & Zechstein & & Fulda-Fm. (z7) & Clst, Sst \\
\hline & & & $\begin{array}{l}\text { Friesland-Fm. (z6) - } \\
\text { Werra-Fm. (z1) }\end{array}$ & $\begin{array}{l}\text { Clst, Dol, Anhy, Gyp, } \\
\text { mrlst }\end{array}$ \\
\hline & Rotliegend & & Unclassified & Sst, Clst, Cgl \\
\hline
\end{tabular}

\section{Sample set and preparation}

The sample set is composed of 707 core and outcrop samples of sandstones, which cover the majority of the Permo-Triassic subunits and their lithological spectrum (Table 1). The sandstones show a high variability in mineralogical composition and type of cementation and can therefore be classified as heterogeneous sandstones. Core samples ( $n=615)$ were collected from the deep wells Obernsees 1, Mürsbach B1 (MueB1), Mürsbach B3 (MueB3), Mürsbach B4 (MueB4), and also from several shallow wells, reaching down to 20-40 m depth (Fig. 1). To include stratigraphic units that could not be sampled from cores, outcrop samples $(n=92)$ were collected.

For the analysis of anisotropy effect, the outcrop samples were prepared as cubes. The macroscopically visible sedimentary bedding planes were aligned parallel to two of the cube's surfaces to perform measurements of $\lambda_{\mathrm{b}}$ and $v_{\mathrm{p}}$ parallel and perpendicular to the stratification. The cores were cut into two halves and measurements were carried out on the resulting flat surfaces across the sedimentary stratification, providing petrophysical values parallel to the sedimentary bedding. Due to negligible tectonic tilting and the subvertical orientation of wellbores, bedding in all core samples is oriented more or less perpendicular to the core axis. 


\section{Analytical methods}

\section{Thermal conductivity measurements}

$\lambda_{\mathrm{b}}$ measurements were performed under both, air and water saturation (deionised water) at ambient conditions $\left(23 \pm 2{ }^{\circ} \mathrm{C}\right.$, atmospheric pressure). We applied the optical scanning method (TCS; Lippmann and Rauen GbR), the accuracy of which is stated as $\pm 3 \%$ (Popov et al. 1999). Drying of the samples was done at $70{ }^{\circ} \mathrm{C}$ for at least $48 \mathrm{~h}$. The water saturation was carried out under vacuum for at least $24 \mathrm{~h}$ at 0.1 bar. To test the reproducibility of measurements, the samples were measured three times each. For air- and water-saturated samples, the mean standard deviation is $2.0 \%$ and $2.5 \%$ of the measured value.

\section{Compressional wave velocity}

$v_{\mathrm{p}}$ was measured under ambient conditions on oven-dried $\left(70^{\circ} \mathrm{C}, 48 \mathrm{~h}\right)$ samples. An ultrasonic logger equipped with piezoelectric stainless steel p-wave transmitter and receiver probes was used. Probes were pressed at the sample surface with a uniform pressure of 1.0 bar. The system operates with a pulse transmission at a frequency of $80 \mathrm{kHz}$ and achieves an accuracy of $\pm 3 \%$. The mean $v_{\mathrm{p}}$ of a sample was determined by the mean value of linear measurement profiles containing multiple measuring points at a distance of $10 \mathrm{~mm}$ across the total length of the sample. In order to test the reproducibility of the method, threefold measurements have been performed on a sample set of 88 plug samples (Ø50 mm; L45 mm) achieving a mean standard deviation of $1.3 \%$ of the measured value.

\section{Porosity}

For $\Phi$ measurements, 323 plug samples (Ø29 mm; L45 mm) were drilled from outcrop samples and cores. For another 384 core samples, the complete core was used for porosity measurements. To avoid clay mineral swelling and damage to the mineral lattice, isopropanol was used as the saturation fluid and the Archimedes' principal was applied for porosity detection. The precision of the porosity value was checked by repeating measurements on a total of 127 plug samples three times (including also some low porous limestone samples of the Muschelkalk subgroup). At porosity values $>1.5 \%$, the mean standard deviation was $1.4 \%$ of the measured value, while at porosities $<1.5 \%$ it was significantly higher with up to $22.7 \%$ of the value. This shows that for porosities $>1.5 \%$, the method gives very significant results. Literature data do not provide an absolute value for the accuracy of the method, however, a very low uncertainty is described (Zinszner and Pellerin 2007). The accuracy is primarily dependent on the error propagation of adherent saturation fluid on the sample surface, the accuracy of the laboratory balance, and the quality of the degree of saturation.

The porosity measured by this method corresponds to the effective porosity of the sample, since the saturation fluid only penetrates the interconnected pore space. Data bias that originates from variations in effective and total porosity therefore cannot be ruled out. By application of the models presented, this aspect must be taken into account, particularly in case of high intra-crystalline porosities or when porosity is determined by other methods such as density log interpretations. 


\section{Mineralogical composition}

Quantitative data on the mineralogical composition were derived from 174 samples through Rietveld analysis (RVA) on powder samples $(<30 \mu \mathrm{m}$ grain size). Samples were ground, using a McCrone micronizing mill and isopropanol as grinding fluid. A Bruker D5000 with Bragg-Brentano geometry at $35 \mathrm{~mA}$ and $40 \mathrm{kV} \mathrm{Cu} \mathrm{K}$ alpha radiation was used for XRD analysis and the diffractograms were quantitatively analyzed using the Rietveld software TOPAS 4.2 of Bruker-AXS. To provide compatibility of mineral weight proportions with porosity data, RVA results were converted from weight to volume fractions, using the calculated mineral grain densities. As illite and muscovite show overlapping peaks in the XRD diffractograms, these mineral fractions are reported as a total volume fraction. 25 samples were measured three times to estimate the reproducibility of the RVA. The maximum standard deviation for a single mineral phase has been 1.8 vol.\% within these samples. The mean standard deviation for quartz has been $0.5 \mathrm{vol} . \%$. In general, the accuracy of the analysis strongly depends on the amount of crystalline mineral phases inside one sample and the degree of overlapping reflections. For main mineral phases ( $>10 \mathrm{vol} . \%$ ), an error of analysis can be estimated to be about 2 vol.\%.

Additional thin section analyses were carried out to identify cement materials and the paragenesis of individual mineral components (e.g., type of lithic fragments) in the sandstone samples.

\section{Matrix thermal conductivity}

We calculated the matrix thermal conductivity $\lambda_{\mathrm{m}}$ according to Eq. 1, using the geometric mean model (Woodside and Messmer 1961a, b; Somerton 1992). $\lambda_{\mathrm{b}}$ is the measured bulk thermal conductivity, $\Phi$ is the measured porosity, and $\lambda_{\mathrm{f}}$ is the thermal conductivity of the pore-filling fluid (water: $0.6 \mathrm{~W} \mathrm{~m}^{-1} \mathrm{~K}^{-1}$; air: $0.026 \mathrm{~W} \mathrm{~m}^{-1} \mathrm{~K}^{-1}$; Kappelmeyer and Hänel 1974).

$$
\lambda_{\mathrm{m}}=\left(\lambda_{\mathrm{b}} \cdot\left(\lambda_{\mathrm{f}}\right)^{-\Phi}\right)^{1 /(1-\Phi)}
$$

The $\lambda_{\mathrm{m}}$ from mineralogical composition data was calculated according to Eq. 2 (Brigaud et al. 1990), where $v_{\mathrm{i}}$ is the mineral volume fraction from RVA and $\lambda_{\mathrm{i}}$ is the specific mineral thermal conductivity derived from Table 2 .

$$
\lambda_{\mathrm{m}}=\prod_{i=1}^{m} \lambda_{\mathrm{i}}^{v_{\mathrm{i}}}
$$

\section{Results and discussion}

\section{Variability of petrophysical and mineralogical data}

The sandstone samples show a very high variability in all measured petrophysical rock parameters. The $\Phi$ values range between 0.7 and $36.7 \%$ (Fig. 2, Table 3). The $\lambda_{\mathrm{b}}$ values from air- and water-saturated measurements range from 0.9 to $4.9 \mathrm{~W} \mathrm{~m}^{-1} \mathrm{~K}^{-1}$ and 1.7 to $5.8 \mathrm{~W} \mathrm{~m}^{-1} \mathrm{~K}^{-1}$, respectively. The measured $v_{\mathrm{p}}$ values are between 826 and $6276 \mathrm{~m} \mathrm{~s}^{-1}$.

There is also a strong variability in the samples mineralogical composition. This is particularly evident in fluctuating contents of quartz (26-97 vol.\%, min-max), illite/ 
Table 2 Thermal conductivities $\lambda_{i}$ of selected mineral phases applied in this study

\begin{tabular}{lll}
\hline Mineral & $\boldsymbol{\lambda}_{\mathbf{i}}\left[\mathbf{W} \mathbf{~}^{-\mathbf{1}} \mathbf{K}^{\mathbf{- 1}}\right]$ & Reference \\
\hline Quartz & 7.7 & Horai (1971) \\
Microcline & $2.4-2.6(2.5)$ & Horai (1971) \\
Anorthite & 1.7 & Horai (1971) \\
Albite & $1.9-2.3$ & Horai (1971) \\
Muscovite & $2.2-2.5(2.35)$ & Horai (1971) \\
Biotite & $1.7-2.3(2.0)$ & Horai (1971) \\
Illite & 1.8 & Brigaud and Vasseur (1989) \\
Mixed layer & 1.9 & Brigaud and Vasseur (1989) \\
Chlorite & $4.3-6.2(5.25)$ & Horai (1971) \\
Kaolinite & 2.6 & Brigaud and Vasseur (1989) \\
Haematite & 11.3 & Horai (1971) \\
Dolomite & 5.5 & Horai (1971) \\
Calcite & 3.6 & Horai (1971) \\
Anhydrite & 4.8 & Horai (1971) \\
\hline
\end{tabular}
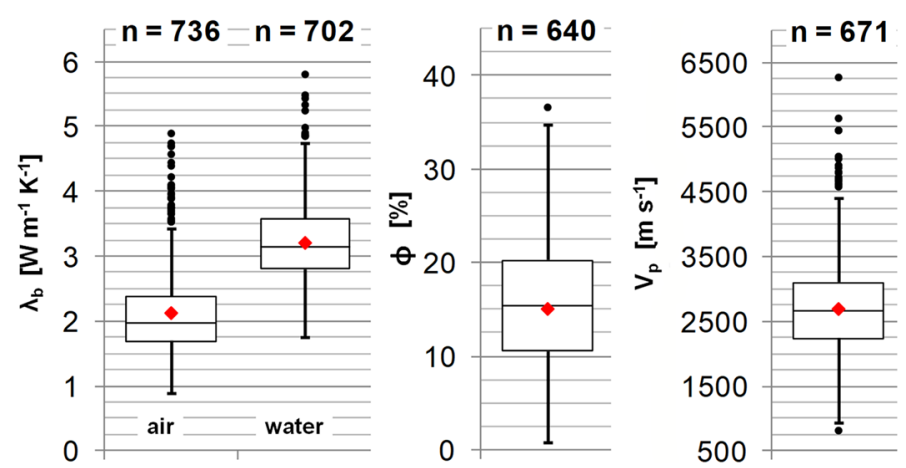

Fig. 2 Boxplots of the petrophysical parameters $\lambda_{b}, \Phi$, and $v_{p}$ measured on Permo-Triassic sandstones; horizontal lines place medians of boxplots and red dots give mean values ( $n=$ number of samples, air $=$ air-saturated sandstones, water $=$ water-saturated sandstones)

Table 3 Statistical parameters of petrophysical and mineralogical data (RVA) measured on Permo-Triassic sandstones

\begin{tabular}{|c|c|c|c|c|c|c|c|c|c|}
\hline Parameter & SI-unit & $n$ & Mean & $\sigma$ & Min & Q1 & Median & Q3 & Max \\
\hline $\begin{array}{l}\lambda_{b}(\text { air-satu- } \\
\text { rated })\end{array}$ & $\mathrm{Wm}^{-1} \mathrm{~K}^{-1}$ & 707 & 2.1 & 0.6 & 0.9 & 1.7 & 2.0 & 2.4 & 4.9 \\
\hline $\begin{array}{l}\lambda_{\mathrm{b}} \text { (water- } \\
\text { saturated) }\end{array}$ & $\mathrm{Wm}^{-1} \mathrm{~K}^{-1}$ & 702 & 3.2 & 0.6 & 1.7 & 2.8 & 3.1 & 3.6 & 5.8 \\
\hline$\Phi$ & vol.\% & 640 & 15.2 & 6.7 & 0.7 & 10.5 & 15.4 & 20.2 & 36.7 \\
\hline$v_{p}$ & $\mathrm{~ms}^{-1}$ & 671 & 2701 & 803 & 826 & 2234 & 2660 & 3101 & 6276 \\
\hline Quartz & vol.\% & 175 & 63.9 & 15.9 & 17.5 & 52.2 & 64.9 & 74.4 & 96.6 \\
\hline
\end{tabular}

muscovite (0-44 vol.\%), alkali feldspar (0-20 vol.\%), and plagioclase (0-20 vol.\%). In addition, the following mineral phases were identified by means of RVA: $0-15$ vol.\% kaolinite, $0-10$ vol.\% chlorite, $0-2$ vol.\% smectite, $0-41$ vol.\% dolomite, $0-6$ vol.\% calcite, 
0-1.9 vol.\% magnesite, $0-4$ vol.\% siderite, $0-26$ vol.\% anhydrite, $0-0.9$ vol.\% gypsum, and $0-15$ vol.\% hematite.

Through optical examination of thin sections, quartz, alkali feldspar, plagioclase, and rock fragments of polyquartz and metamorphites were identified as the main detrital components. The sandstones are dominantly cemented by authigenic clay and subordinately by quartz. However, there are also sandstones which are cemented by carbonate with carbonate volume fractions reaching up to 41 vol.\%. Carbonate cements are mainly composed of dolomite with a calcite volume fraction of usually $<1$ vol.\% (RVA). Higher calcite volume fractions of 1.4 to 6.0 vol.\% were only detected in four sandstones samples. Based on the mineralogical characterization, the sandstone sample set can therefore be classified as heterogeneous sandstones with a highly variable mineralogical composition.

If no significant amount of dolomite is present in the sandstone samples, quartz, feldspar, and clay minerals represent 87 to 100 vol.\% of the RVA-derived mineral fraction. Mineralogical compositions of the stratigraphic subunits Keuper, Buntsandstein, Zechstein, and Rotliegend generally show overlapping data points, with Buntsandstein sandstone samples tending to bear higher quartz volume fractions compared to all other subunits (Fig. 3).

The results reveal extreme ranges in all measured sandstone parameters. This confirms that the use of published averages for $\lambda_{\mathrm{b}}$ or any other rock properties of sandstones will necessarily cause significant uncertainties or even misleading results. With respect to geothermal applications, this in turn demonstrates the necessity of suitable models for achieving reliable bulk thermal conductivities of sandstones, which are valid for a high range in mineralogical compositions. As already described above, however, the suitability of a model must be evaluated with respect to the measurement conditions under which the data for an individual model are generated.

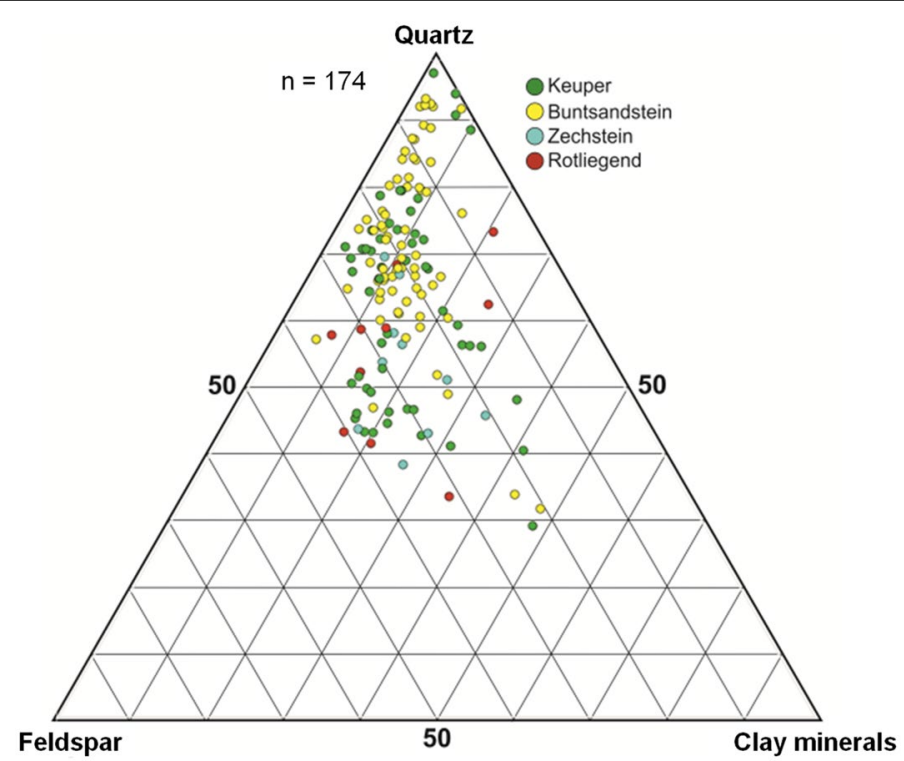

Fig. 3 Ternary diagram of RVA results (vol.\%) of sandstones using quartz, feldspar, and clay minerals as endmembers 


\section{Controls on matrix thermal conductivities}

\section{Comparison of methods for $\lambda_{\mathrm{m}}$ determination}

The parameter $\lambda_{\mathrm{m}}$ often is a key variable in empirical or theoretical models but cannot be measured directly. Instead, it is calculated, but the methods applied vary. Figure 4a shows a comparison of $\lambda_{\mathrm{m}}$ calculated from $\lambda_{\mathrm{b}}$ measurements of air- and water-saturated sandstone samples according to Eq. 1 . For the majority of the samples, $\lambda_{\mathrm{m}}$ calculated from both, air-saturated and water-saturated measurements is in good agreement. Minor deviations are related to the accuracy of the method. However, for some samples, the values calculated from measurements of air-saturated sandstones are significantly higher than those calculated from measurements of water-saturated samples. This observation is in line with the results of Fuchs et al. (2013), who found an on average $4.9 \%$ higher $\lambda_{\mathrm{m}}$ value associated with dry sandstone samples. This implies that despite the general enhancement of $\lambda_{\mathrm{b}}$ in case of water saturation, the calculated value of $\lambda_{\mathrm{m}}$ can be reduced due to the presence of water in the pores. This process is a possible explanation for the non-linear relation of the bulk thermal conductivity of sandstones with water saturation (Jorand et al. 2011).

Another method to calculate $\lambda_{\mathrm{m}}$ is the use of quantitative mineralogical data, assuming standard thermal conductivities of single mineral phases (Eq. 2, Table 2). The main uncertainties of this method are errors in the calculated volume fraction of the individual mineral phases and in the determination of specific mean thermal conductivities of the mineral phases. In Fig. $4 \mathrm{~b}, \lambda_{\mathrm{m}}$ values calculated from mineralogical data (RVA) are compared to $\lambda_{\mathrm{m}}$ values calculated from $\lambda_{\mathrm{b}}$ measurements of air- and water-saturated sandstones. For the vast majority of samples, RVA data-derived $\lambda_{\mathrm{m}}$ values are significantly higher than those obtained from the $\lambda_{\mathrm{b}}$ measurements. This is true for both tested saturation fluids. Outliers from this trend are the same samples which plotted as outliers in Fig. 4a, due to their significantly higher $\lambda_{\mathrm{m}}$ values calculated from $\lambda_{\mathrm{b}}$ measurements of air-saturated sandstones. The results of the test of different methods for the calculation of $\lambda_{\mathrm{m}}$ reveal two fundamental problems in the application of the theoretical geometric mean model (Eq. 1):

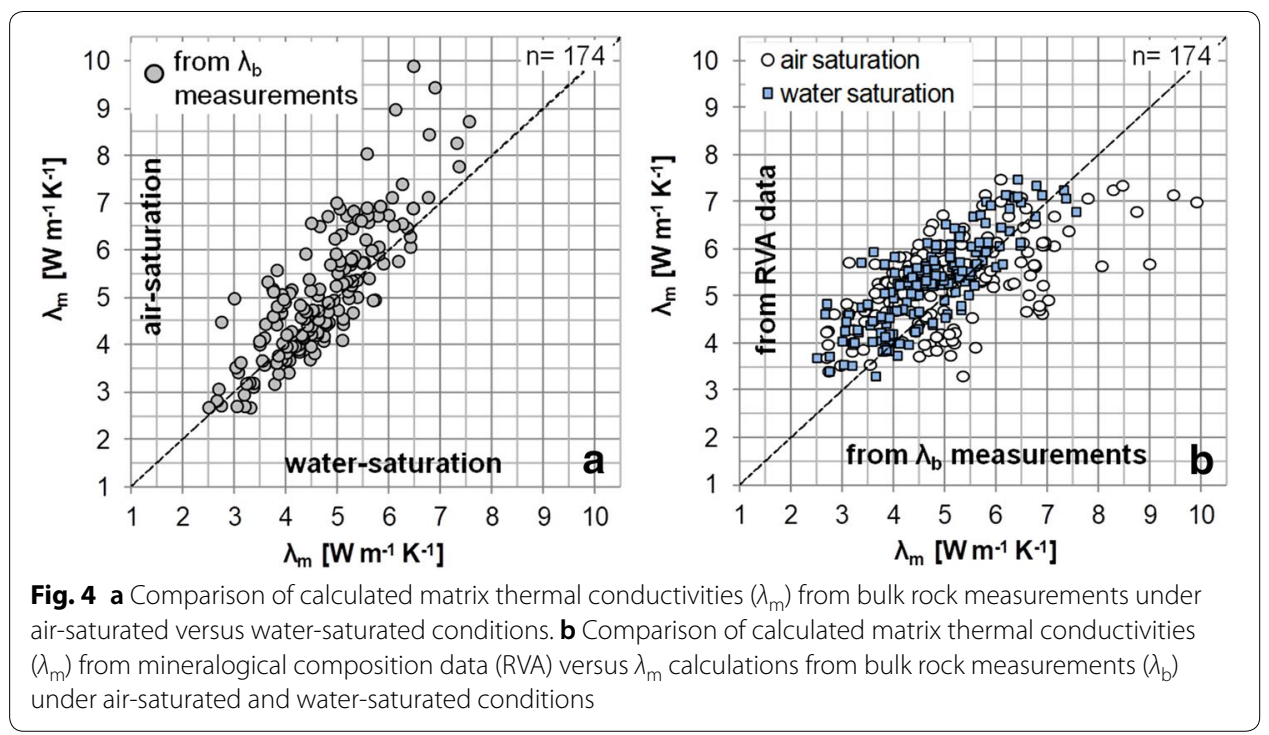


- The assumption that $\lambda_{\mathrm{b}}$ measurements of air- and water-saturated sandstone samples should lead to identical $\lambda_{\mathrm{m}}$ values does not apply to all sandstones. Conversely, this implies that a conversion from "dry" air-saturated to water-saturated conditions using the geometric mean model can be associated with considerable errors for specific sandstones samples (Fig. 4a).

- When using mineralogical data for calculation of $\lambda_{\mathrm{m}}$, the actual $\lambda_{\mathrm{m}}$ value generally tends to be overestimated (Fig. 4b).

The question arises why the $\lambda_{\mathrm{m}}$ values of some sandstone samples, measured under air-saturated conditions are significantly higher than those of the corresponding measurements in a water-saturated state. The potential control factors for the matrix thermal conductivity of porous sandstones are primarily the porosity and the mineralogical composition of the samples which will be evaluated in the following chapter.

\section{The relative impact of individual mineral phases on $\lambda_{m}$}

To identify the relative impact of single mineral phases on $\lambda_{\mathrm{m}}$, we carried out a multiple linear regression analysis with $\mathrm{R} \odot$ (R Development Core Team 2008), using quantitative mineralogical compositions and porosity data of 174 sandstone samples as variables. In the case of mineral absence or measurements below detection limit, we set a minimum percentage of $0.0001 \%$ to avoid zero values. The regression analysis was carried out for both, $\lambda_{\mathrm{m}}$ values from air- and from water-saturated measurements, and included the stepwise elimination of insignificant variables.

The calculated parameters and coefficients of significant variables (defined by $p$-values $<0.05$ ) derived from the regression analysis (e.g., coefficients of determination, standard error) are listed in Table 4 for both models. The results show that for both types of pore fluids tested, the same variables exert an influence on the thermal properties of the rock matrix, but to varying degrees. In addition to porosity, $\lambda_{\mathrm{m}}$ is primarily

Table 4 Regression coefficients of multiple regression models of the variable $\lambda_{m}$ for airand water-saturated sandstones

\begin{tabular}{|c|c|c|c|c|c|c|}
\hline Pore fluid & $\begin{array}{l}\text { Variable/ } \\
\text { predicator }\end{array}$ & Coefficient & Standard error & $t$ value & $p$ value & $R^{2}$ \\
\hline \multirow[t]{6}{*}{ Air } & Intercept & 1.74 & 0.56 & 3.11 & $2.22 \times 10^{-3}$ & 0.65 \\
\hline & Porosity & 0.079 & 0.010 & 7.85 & $4.66 \times 10^{-13}$ & \\
\hline & Quartz & 0.0410 & 0.0057 & 7.18 & $2.12 \times 10^{-11}$ & \\
\hline & Alkali feldspar & -0.044 & 0.014 & -3.22 & $1.55 \times 10^{-3}$ & \\
\hline & Kaolinite & 0.117 & 0.026 & 4.46 & $1.48 \times 10^{-5}$ & \\
\hline & Dolomite & 0.0226 & 0.0086 & 2.64 & $8.99 \times 10^{-3}$ & \\
\hline \multirow[t]{7}{*}{ Water } & Intercept & 1.53 & 0.37 & 4.08 & $6.97 \times 10^{-5}$ & 0.72 \\
\hline & Porosity & 0.022 & 0.0065 & 3.31 & $1.15 \times 10^{-3}$ & \\
\hline & Quartz & 0.048 & 0.0038 & 12.54 & $2.0 \times 10^{-16}$ & \\
\hline & Alkali feldspar & -0.023 & 0.0090 & -2.51 & $1.31 \times 10^{-2}$ & \\
\hline & Kaolinite & 0.055 & 0.017 & 3.26 & $1.36 \times 10^{-3}$ & \\
\hline & Dolomite & 0.025 & 0.0056 & 4.51 & $1.23 \times 10^{-5}$ & \\
\hline & Siderite & -0.29 & 0.12 & -2.51 & $1.30 \times 10^{-2}$ & \\
\hline
\end{tabular}


controlled by the volume fractions of quartz, alkali feldspar, kaolinite, and dolomite. The water-saturated model also comprises the mineral siderite as a significant variable. A model including these variables can explain $66 \%$ of the $\lambda_{\mathrm{m}}$ variance of air-saturated sandstones and $74 \%$ of the variance under water-saturated conditions (Table 4). Other mineral phases identified in the RVA do not show significant effects on $\lambda_{\mathrm{m}}$ variability.

A closer look at the coefficients in Table 4 reveals that porosity has significantly higher influence on $\lambda_{\mathrm{m}}$ when the pores are air-saturated, whereas in case of a water-saturated pore space, the mineralogical composition is identified as the strongest controlling factor. This is well reflected by the significantly higher coefficient of determination $\left(R^{2}\right)$ of 0.72 for water-saturated, compared to air-saturated conditions $\left(R^{2}=0.65\right)$ (Fig. 5, Table 4). The less significant fit under air-saturated conditions is also related to the exponential relationship between porosity and bulk thermal conductivity of sandstones, which will be analyzed in the section "suitability of sandstone parameters for thermal conductivity proxies" to closer detail. An alternative exponential trend line construction would improve the fit for the air-saturated model (Fig. 5a). The remaining variance of both regression models is likely related to the combined effects of instrument error during $\lambda_{\mathrm{b}}$ measurements and structural parameters like the types of grain contacts or the shapes of pores, which were not considered in the model.

The results of the multiple linear regression analysis (Table 4) also allow the quantification of the individual impact of specific mineral phases on the parameter $\lambda_{\mathrm{m}}$. While quartz and dolomite volume fractions both exert strong influence in case of both tested pore fluids, the effects of alkali feldspar and kaolinite are significantly different. This can be attributed to the weathering of alkali feldspar, a feature which was primarily observed in Upper Triassic (Keuper) sandstones. On the one hand, the alteration of alkali feldspar (Fig. 6a, b) leads to a reduction of its original mineral thermal conductivity when the sandstone's pore space is saturated by air. On the other hand, the kaolinite precipitation in the pore space (Fig. 6c, d) simultaneously increases the conductivity of the rock matrix. This improvement in $\lambda_{\mathrm{m}}$ due to the precipitation of authigenic kaolinite is interpreted as the result of improved grain contacts of detrital sandstone components. Carson et al. (2003) found that the quantitative contact area between components of porous

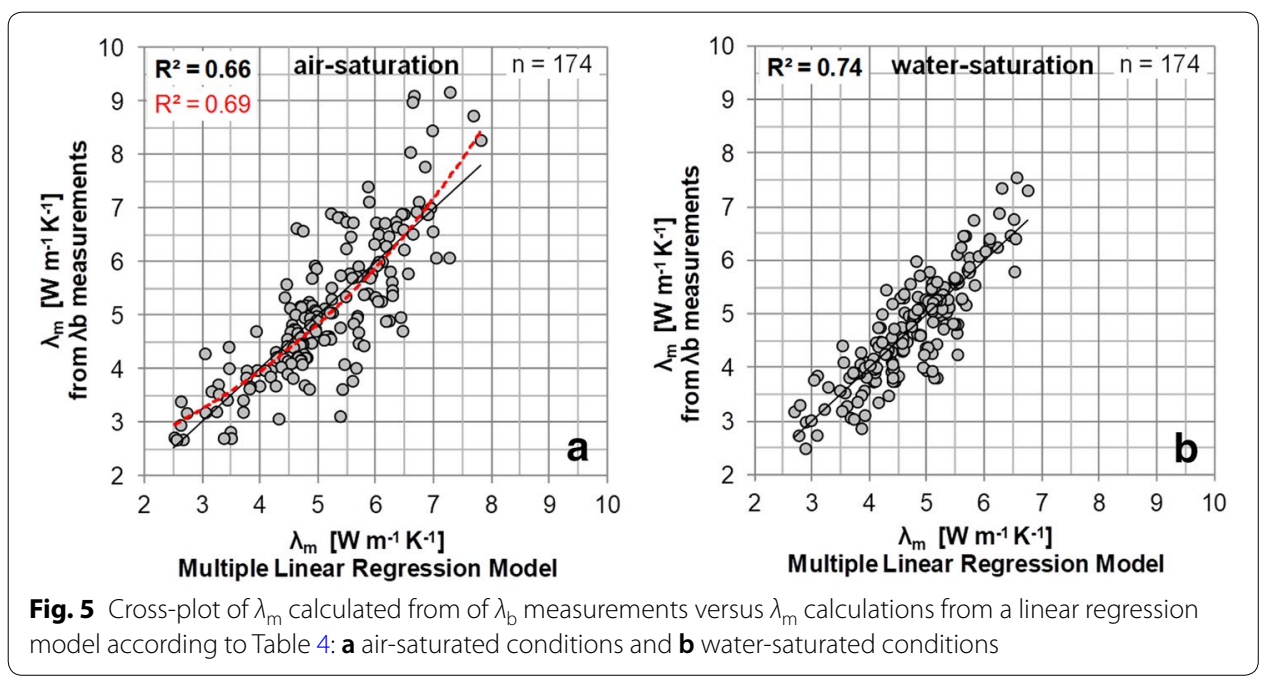




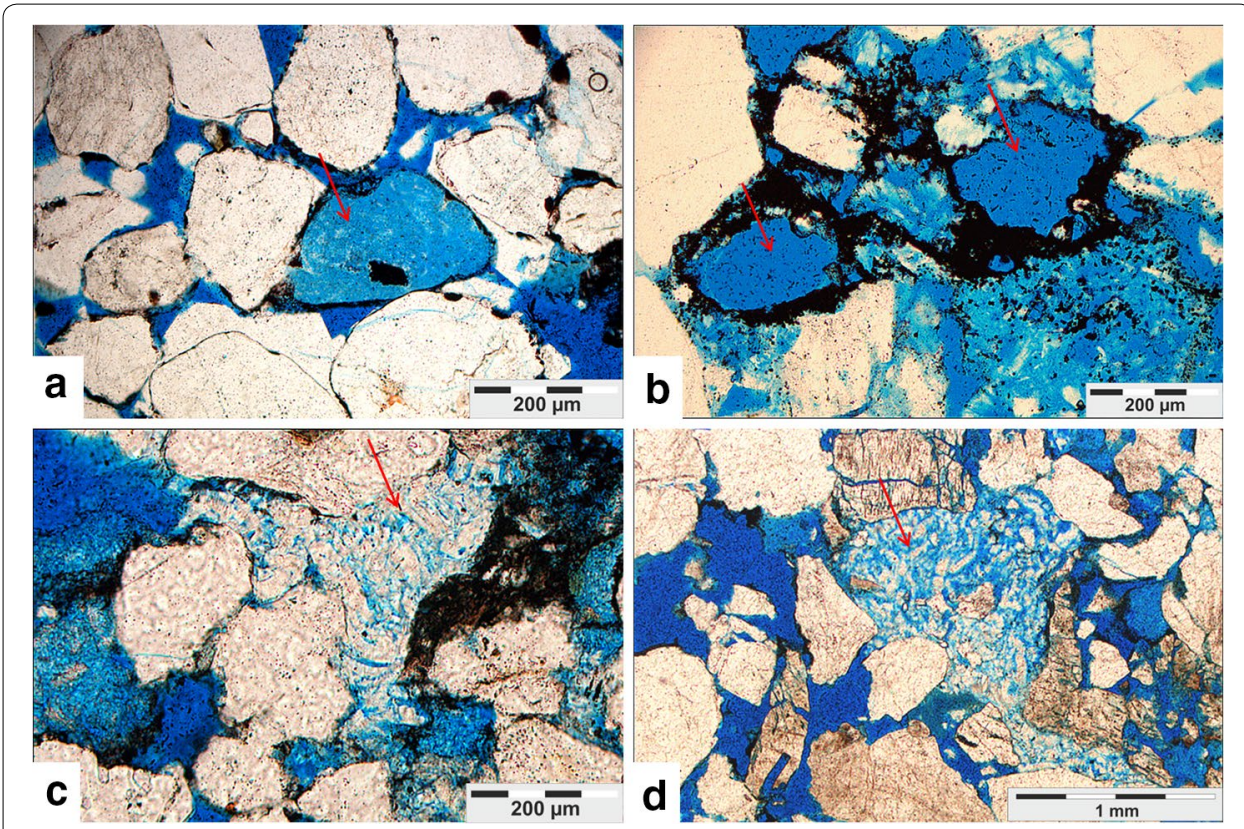

Fig. 6 Thin section photographs of sandstone samples (blue stained epoxy), showing a altered alkali feldspar showing dissolution effects (red arrow), $\mathbf{b}$ ferrogeneous ghost structure remains of completely dissolved alkali feldspar (red arrows), c, d authigenic, worm-like kaolinite booklets (red arrows), resulting from alkali feldspar degeneration (a Buntsandstein sandstone, Hardegsen Formation; b-d Keuper sandstone, Löwenstein Formation/Upper Burgsandstein)

materials is more important for their thermal properties than the size or shape of individual pores or components. The effect of kaolinite precipitation and alteration of alkali feldspar is less pronounced in the case of water-saturated sandstones, since the reduction of the thermal conductivity differences between the pore fluid and rock matrix also leads to an improvement in the conductive contact between the individual rock components. This effect applies to the alkali feldspars affected by phase transformation with development of intragrain porosity, too. The control of water saturation is also evidenced by the fact that the regression coefficients (Table 4) of alkali feldspar and kaolinite in the water-saturated model are approximately halved compared to the values determined for the air-saturated model (Table 4). This ratio is similar to the ratio of the thermal conductivity values of air $\left(0.026 \mathrm{~W} \mathrm{~m}^{-1} \mathrm{~K}^{-1}\right)$ and water $\left(0.06 \mathrm{~W} \mathrm{~m}^{-1} \mathrm{~K}^{-1}\right)$.

The evaluation of the main control factors on $\lambda_{\mathrm{m}}$ of the sandstones investigated here shows that the application of the geometric mean model for the transformation of thermal conductivities measured on air-saturated sandstones to water-saturated conditions can be highly error prone in specific sandstone types. Additionally, in the case of $\lambda_{\mathrm{m}}$ calculation from a mineralogical database, a general overestimation of $\lambda_{\mathrm{m}}$ can be expected (Fig. 4b), at least for those sandstone types which were investigated in this study. This is a valuable information when mineralogical data are used to compute the parameter $\lambda_{\mathrm{m}}$.

The increase in matrix thermal conductivity due to the swelling of clay minerals described in other studies (e.g., Albert et al. 2017) is irrelevant for the sandstones investigated in this study. Although low volume fractions of smectite were detected in some of the samples, illite is identified as the predominant clay mineral. 


\section{Method-dependent influence of anisotropy effects}

The influence of anisotropy effects in sandstones depends mainly on the presence of sedimentary bedding structures and their orientation relative to the axis of the measurement signal. Therefore, an anisotropic behavior can be expected for the measurements of $\lambda_{\mathrm{b}}$ and $v_{\mathrm{p}}$ in the course of this study. Both rock parameters do show anisotropy in case of air-saturated samples, resulting in generally higher $\lambda_{\mathrm{b}}$ (Fig. 7a) and $\nu_{\mathrm{p}}$ (Fig. 7b) values when measurements are conducted parallel to the sedimentary bedding planes. This is in line with findings of other studies (e.g., Brigaud and Vasseur 1989). The strength of anisotropy effects is mirrored by the range of the anisotropy ratios (measurements parallel versus measurements perpendicular to bedding planes). Anisotropy ratios for $v_{\mathrm{p}}(0.90-$ 1.38) are significantly higher, compared to the range of anisotropy ratios $(0.89-1.15)$ for $\lambda_{\mathrm{b}}$ measurements of air-saturated sandstones. In contrast, for water-saturated measurement conditions of $\lambda_{\mathrm{b}}$, the data points show a more scattered distribution of the measurements parallel and perpendicular to sandstone bedding, without providing a clear trend (Fig. 7a). This implies that the anisotropy effects are significantly attenuated by the reduced thermal conductivity contrast between the pore fluid and the rock matrix. The higher scatter of the data points is probably due to higher standard errors which might be expectable at water-saturated conditions. One possible cause here is water loss during the measurement process, e.g., by rinsing and evaporation of water.

The quantitative differences in the anisotropy effects for $v_{\mathrm{p}}$ and $\lambda_{\mathrm{b}}$ of air-saturated samples are mainly caused by the different signal detection routines for both methods. To determine $v_{\mathrm{p}}$, transmitter and detector are placed at the top and the bottom of the sample. The ultrasonic signal must pass through the entire diameter of the sample, and therefore, is affected by all internal fabrics of the sample. In contrast, during $\lambda_{\mathrm{b}}$ measurements with the TCS, the surface temperature of the sample is measured at the same measurement point before and after a short heating period. Thus, the heat flow does not have to pass through the entire sample diameter and consequently parameter $\lambda_{\mathrm{b}}$ is much less affected by the internal structure of the sample. From these observations, we interpret that anisotropy effects become generally much more visible when a measurement signal has to pass through the entire diameter and all the different sediment

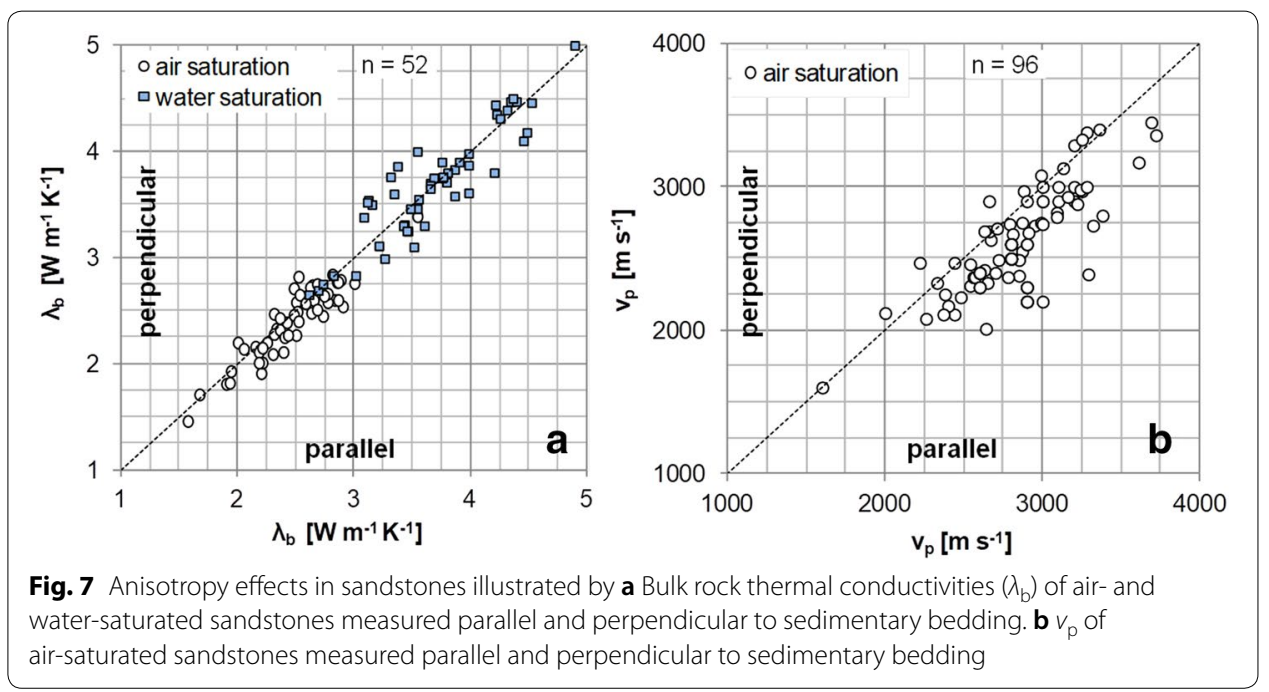


layers contained. Especially in inhomogeneous sandstones with variable mineralogical composition of the different sediment layers, anisotropy effects are expected to be more pronounced compared to massive, homogeneous, and/or more or less monomineralic sandstones or other rock types.

\section{Suitability of sandstone parameters for thermal conductivity proxies Correlation of $\lambda_{b}$ with $\Phi$ values}

In order to test the suitability of different sandstone parameters as thermal conductivity proxies and their dependence on the type of pore fluid, a systematic series of thermal conductivity measurements using air- and water-saturated samples was performed. The $\lambda_{\mathrm{b}}$ values for both measurement conditions were correlated with the sandstone parameters $\Phi$ and $v_{\mathrm{p}}$ as well as with quantitative mineralogical data, derived from RVA. As outlined in the former section, anisotropy effects must be considered in the setup of empirical models that are based on the correlation of rock parameters. This is especially required when two or more rock parameters are correlated, of which each is showing an anisotropic behavior. As the $\lambda_{\mathrm{b}}$ of core samples could only be measured parallel to sedimentary bedding, we uniformly used these values for regression analysis.

The correlation of $\Phi$ and $\lambda_{\mathrm{b}}$ provides a significant difference in $R^{2}$ for air- and watersaturated sandstone samples. The dry samples show an exponential relationship $\left(R^{2}=0.60\right)$ of increasing $\lambda_{\mathrm{b}}$ with decreasing $\Phi$ values (Fig. 8a). In case of water-saturated sample conditions, however, this correlation is insignificant (Fig. 8b). This indicates that individual porosity models for $\lambda_{\mathrm{b}}$ estimation of sandstones are not simply transferable to water-saturated conditions-conditions which might be expected in the subsurface. The influence of porosity on $\lambda_{\mathrm{b}}$ decreases with decreasing difference between the thermal conductivity of the fluid in pores/cracks and the rock matrix (Walsh and Decker 1966). The exponential relation of $\Phi$ and $\lambda_{\mathrm{b}}$ is in accordance with results reported for other rocks types (e.g., Sugawara and Yoshizawa 1961; Brigaud and Vasseur 1989; Aurangzeb et al. 2006). The mineralogical data show that for porosity values of $<20 \%$, sandstone

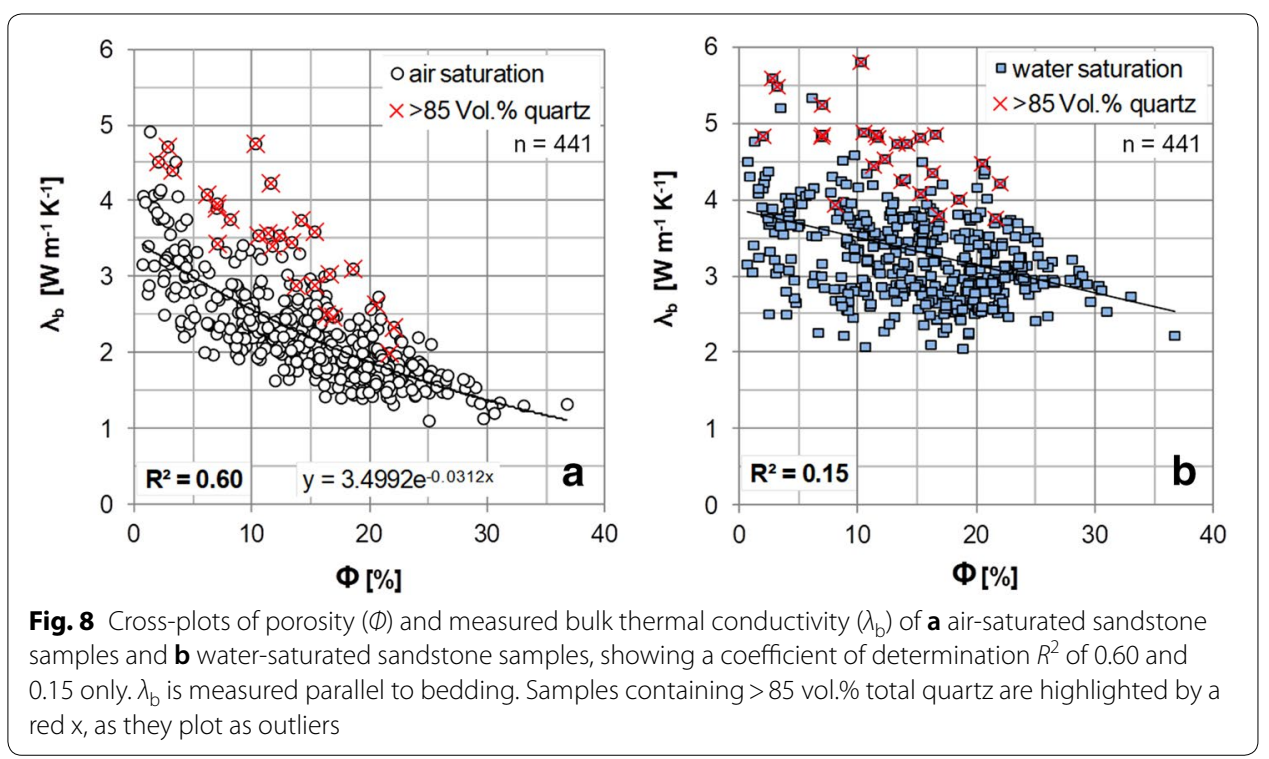


samples with $>85$ vol.\% quartz content clearly plot outside of the general trend line, as they are showing increased thermal conductivity values (Fig. 8a). The non-linear increase of $\lambda_{\mathrm{b}}$ for samples with $>85$ vol.\% quartz becomes enhanced with decreasing porosity. This implies for porosities below $20 \%$ a superposition of the porosity effect on $\lambda_{\mathrm{b}}$ values by an increasing influence of total quartz contents on the thermal conductivity. For air-saturated sandstones, Fig. 8 a suggests that porosities of $<5 \%$ no longer have a significant impact on $\lambda_{\mathrm{b}}$ values. Our results do not only confirm that at low porosities, existing porosity models become insignificant (Jorand et al. 2015), but also that in case of water saturation, porosity models are generally object of large errors and not suitable for the prediction of $\lambda_{\mathrm{b}}$ under water-saturated conditions to be expected in the subsurface.

\section{Correlation of $\lambda_{b}$ with $v_{p}$ values}

Compared to the relation of $\Phi$ and $\lambda_{\mathrm{b}}$ (Fig. 8), cross-plots of $v_{\mathrm{p}}$ and $\lambda_{\mathrm{b}}$ of air-saturated sandstones imply a more significant correlation $\left(R^{2}=0.74\right)$ (Fig. 9a). The $\lambda_{\mathrm{b}}$ values exponentially increase with increasing $v_{\mathrm{p}}$ values. Although $\Phi$ and $v_{\mathrm{p}}$ are known to show a close correlation (e.g., Wyllie et al. 1956; Esteban et al. 2015), the parameter $v_{\mathrm{p}}$ is identified as the more significant proxy for the $\lambda_{\mathrm{b}}$ of sandstones-especially when the pore space is saturated by air. The better correlation of $v_{\mathrm{p}}$ and $\lambda_{\mathrm{b}}$, compared to the scatter plot correlating $\lambda_{\mathrm{b}}$ and $\Phi$ (Fig. 8a) might be explained by the impact on $v_{\mathrm{p}}$ of additional structural features such as grain contacts and sedimentary bedding as well as the density of individual detrital and authigenic components. These parameters also have a strong control on the thermophysical properties of the sandstones. In contrast to porosity (Fig. 8a), the significant correlation of $v_{\mathrm{p}}$ and $\lambda_{\mathrm{b}}$ for air-saturated samples is also valid for sandstones with quartz volumes $\left(v_{\text {quartz }}\right)$ of $>85$ vol.\% (Fig. 9a). This assigns the $v_{\mathrm{p}}$ value as a more promising proxy in empirical models for of $\lambda_{\mathrm{b}}$ prediction and estimation. However, the above-average increase in the $\lambda_{\mathrm{b}}$ values of the quartz-rich samples ( $>85 \mathrm{vol} . \%$ quartz) is also visible in the $\lambda_{\mathrm{b}}$ versus $v_{\mathrm{p}}$ plot (Fig. 9a) by a broader and more scattered deviation of the specific sample points from the general trend line.
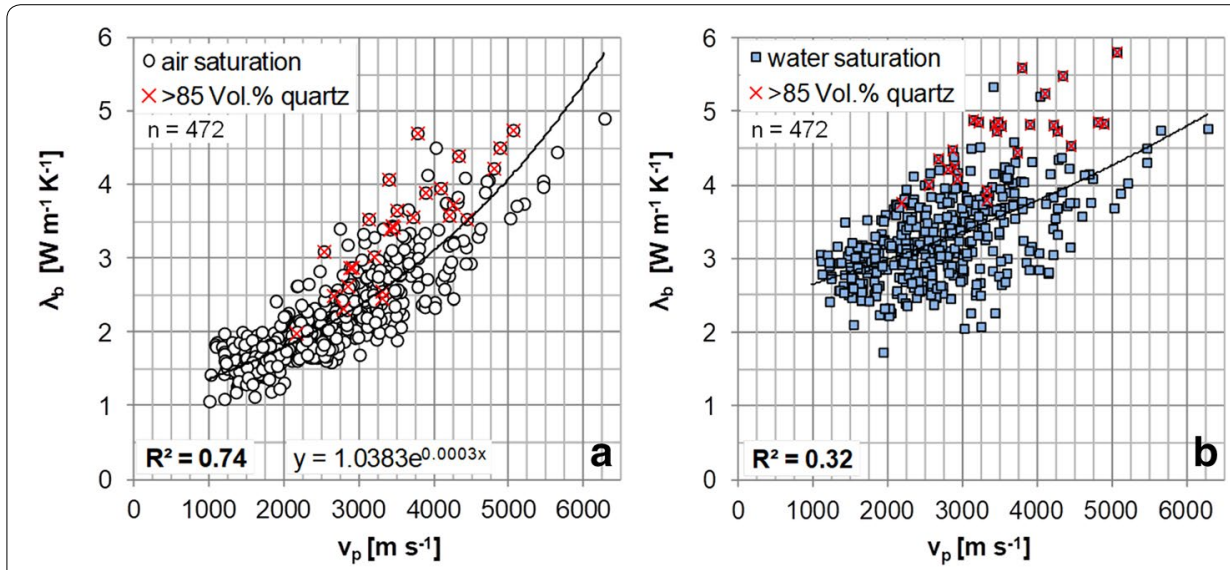

Fig. 9 Cross-plots of P-wave velocities $v_{p}$ (air-saturated samples) and bulk thermal conductivities $\left(\lambda_{b}\right)$ of $\mathbf{a}$ air-saturated sandstone samples and $\mathbf{b}$ water-saturated sandstone samples, revealing a coefficient of determination $R^{2}$ of 0.74 and $0.32 . \lambda_{\mathrm{b}}$ and $v_{\mathrm{p}}$ are measured parallel to the orientation of the sedimentary stratification bedding. Samples containing $>85$ vol.\% total quartz are highlighted by a red $x$, as they plot as outliers 
Analogous to the relation between $\Phi$ and $\lambda_{\mathrm{b}}$, the correlation of $v_{\mathrm{p}}$ with $\lambda_{\mathrm{b}}$ becomes insignificant in the case of water-saturated samples (Fig. 9b). This can be explained by an effect already described for the porosity plots (Fig. 8), which is a decreasing influence of porosity with decreasing thermal conductivity differences between rock matrix and pore fluid. This observation suggests that $v_{\mathrm{p}}$ models for sandstones calibrated by "dry" $\lambda_{\mathrm{b}}$ and/or $\mathrm{v}_{\mathrm{p}}$ measurements (e.g., Gegenhuber and Schön 2012; Özkahraman et al. 2004) might not be readily transferable to saturated conditions, for example, if the thermal conductivity is calculated from acoustic logs (Gegenhuber and Schön 2012; Gegenhuber and Kienler 2017). A more significant correlation between $v_{\mathrm{p}}$ and $\lambda_{\mathrm{b}}$ might be achieved, however, by using $v_{\mathrm{p}}$ measurements of water-saturated samples, but this is not verified yet.

\section{Mineralogical composition and $\lambda_{b}$ values}

The mineralogical composition of sandstones is a decisive factor for their $\lambda_{\mathrm{b}}$ values (e.g., Birch and Clark 1940; Horai and Baldridge 1972; Clauser and Huenges 1995; Andrés et al. 2016). Due to the significantly higher thermal conductivity of quartz compared to that of clay minerals and feldspars (Table 4), the total quartz content (detrital+authigenic quartz) of sandstones is considered to be one of the main control factors on its thermal properties. In a test of the proxy suitability of the quartz volume fraction $\left(v_{\text {quartz }}\right)$ for the estimation of the sandstone $\lambda_{\mathrm{b}}$ value, there are clear differences in the significance of quartz, dependent on the pore fluid type. While the cross-plot of $v_{\text {quartz }}$ versus $\lambda_{\mathrm{b}}$ of air-saturated sandstones is insignificant (Fig. 10a1), water-saturated samples show a positive linear correlation, although with a relatively low $R^{2}$ of only 0.42 (Fig. 10b1). In comparison to the parameters $\Phi$ and $v_{\mathrm{p}}$ (Figs. 8, 9), the significance of the regression trend with respect to the type of the pore fluid is reversed.

Of both pore fluid conditions tested, samples with very low porosities $<5 \%$ and dolomite fractions of $>20 \mathrm{vol}$ \% plot as outliers, as they show enhanced $\lambda_{\mathrm{b}}$ values (Fig. 10a1, b1). Although dolomite $\left(5.5 \mathrm{~W} \mathrm{~m}^{-1} \mathrm{~K}^{-1}\right)$ has a lower thermal conductivity than quartz (7.7 $\mathrm{W} \mathrm{m}^{-1} \mathrm{~K}^{-1}$ ), its specific thermal conductivity is considerably higher compared to feldspars and clay minerals frequently found in sandstones (Table 2). The correlation of $v_{\text {quartz }}$ with $\lambda_{\mathrm{b}}$ can be considerably improved when the dolomite volume fraction is considered, too. The sum of quartz and dolomite $\left(v_{\text {quartz }}+\right.$ dolomite $)$ correlated with $\lambda_{\mathrm{b}}$ gives a significant improvement in significance $\left(R^{2}=0.53\right)$ (Fig. 10b2) compared to Fig. $10 \mathrm{~b} 1$. However, despite improving $R^{2}$ for both tested pore fluids, this relationship still remains insignificant in the case of air-saturated samples (Fig. 10a2).

The lack of a close correlation between $v_{\text {quartz }}$ and $\lambda_{\mathrm{b}}$ in case of air-saturated sandstones (Fig. 10a1) can be explained by the strong influence of porosity (Fig. 8a). While the mineralogical components of the sandstones are conductively poorly connected due to the insulating properties of air, the conductive heat transfer between rock matrix components becomes significantly better when pores are saturated by water. This is also supported by the observation that samples with very low porosities $(<5 \%)$ show a much steeper trend of increasing $\lambda_{\mathrm{b}}$ values with increasing $v_{\text {quartz }}$ or $v_{\text {quartz }}+$ dolomite values. 


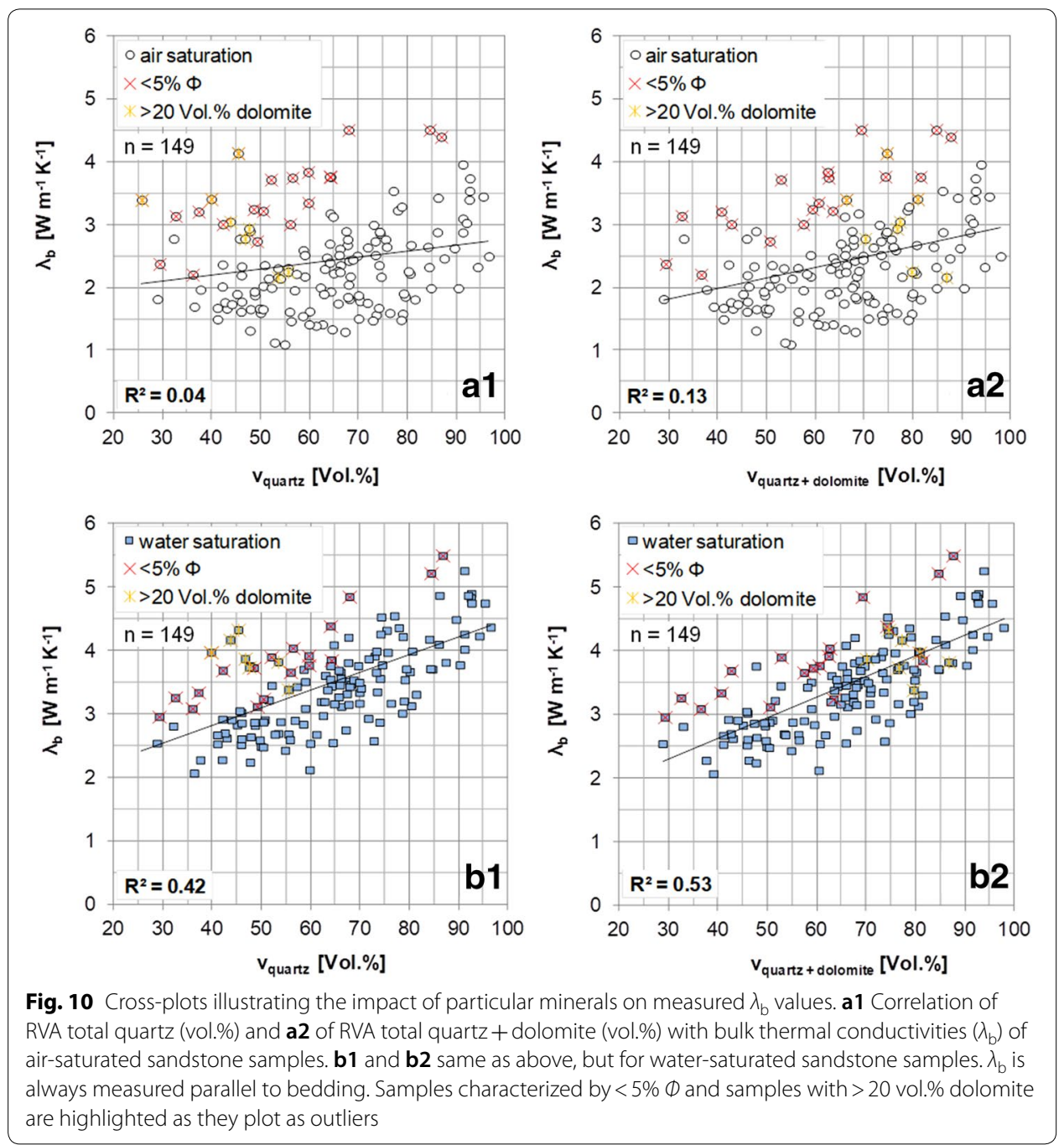

\section{New pore-fluid-dependent combinations for $\lambda_{b}$ proxies}

The results of this study show that empirical models for the estimation of sandstone $\lambda_{\mathrm{b}}$ from other rock properties should be calibrated by a combination of rock parameters to be valid for different types of pore fluids. As a single parameter, none of the tested rock properties provided sufficient accuracy for the estimation of $\lambda_{\mathrm{b}}$ in the case of mineralogically heterogeneous sandstones investigated here.

The mineralogical composition gains an increasing influence on the $\lambda_{\mathrm{b}}$ value of sandstones with decreasing $\Phi$ and decreasing difference in thermal conductivity between the rock matrix and pore fluid (e.g., water) (Figs. 8, 9, 10). In contrast, at higher thermal conductivity contrasts like in case of air-filled pores, the $\Phi$ and structural parameters (represented by $v_{\mathrm{p}}$ ) are the main controls on $\lambda_{\mathrm{b}}$.

This suggests that for different pore fluids in sandstones, it is necessary to use different parameter combinations for the valid estimation of thermal conductivity. Since watersaturated conditions are more appropriate for the subsurface in situ conditions, empirical models for the $\lambda_{\mathrm{b}}$ estimation of water-saturated sandstones are of significantly higher scientific interest. 
The easily measurable parameter $v_{\mathrm{p}}$ in combination with mineralogical data is a suitable proxy for the $\lambda_{\mathrm{b}}$ estimation of water-saturated sandstones. $v_{\mathrm{p}}$ is not only affected by $\Phi$ (Filomena et al. 2012), but also by the density of the rock matrix (and thus indirectly by its mineralogical composition) as well as by structural parameters such as the type of grain contacts. The product of $v_{\text {quartz }}$ and $v_{\mathrm{p}}$ gives a significant $R^{2}$ of 0.75 for the water-saturated sandstone samples (Fig. 11b). If both the sandstones quartz and dolomite contents $\left(v_{\text {quartz }}+\right.$ dolomite $)$ are included, the significance of this correlation can be improved even further to a $R^{2}$ value of 0.79 (Fig. 11c). Both models also represent samples with $>85$ vol.\% $v_{\text {quartz }}$, which formed outliers in the individual plots of $\Phi$ (Fig. 8) and $v_{\mathrm{p}}$ versus $\lambda_{\mathrm{b}}$ (Fig. 9). The need of the inclusion of mineralogical data for $\lambda_{\mathrm{b}}$ models under saturated conditions is also supported by studies of clean sandstones (e.g., Esteban et al. 2015), but has not yet been validated for heterogeneous sandstones. The scattering of the sample points in Fig. 11b, c suggests that the error of the models presented herein increases with decreasing $v_{\text {quartz }}$ of the samples. In case of air-filled pore space, however, this proxy combination would be subject to considerable errors (Fig. 11a).

Instead, for air-saturated pore space, the product of the $v_{\text {quartz }} / \Phi$ ratio and $v_{\mathrm{p}}$ provides a much better empirical model for $\lambda_{\mathrm{b}}$ estimation as shown by an $R^{2}$ of 0.85 (Fig. 12a). Similar to the best fit for water-saturated conditions (Fig. 11b, c), this model is also valid for samples with $>85$ vol.\% $v_{\text {quartz }}$. Whereas individual $\Phi$ and $v_{\mathrm{p}}$ models (e.g., Pimienta et al. 2014) are only applicable to "clean" quartzose sandstones, the combined $\Phi, v_{\mathrm{p}}$, and $v_{\text {quartz }}$ model presented here is also valid for heterogeneous, air-saturated sandstones with highly variable mineralogical compositions. However, if the pores are saturated by water, $\lambda_{\mathrm{b}}$ of these samples is also inadequately imaged by the integration of $\Phi$ (Fig. 12b). In this case, consideration of mineralogical data of high thermally conductive mineral fractions combined with $\mathrm{v}_{\mathrm{p}}$ provide the more accurate model (Fig. 11b, c).

The remaining variance of the regression models presented herein is likely related to the instrument error of $\lambda_{\mathrm{b}}$ and $v_{\mathrm{p}}$ measurements as well as to other parameters which could not be included in the model. These might be e.g., structural parameters, whose influence increases with decreasing thermal conductivity difference between the pore fluid and the rock matrix (Coté and Konrad 2009).
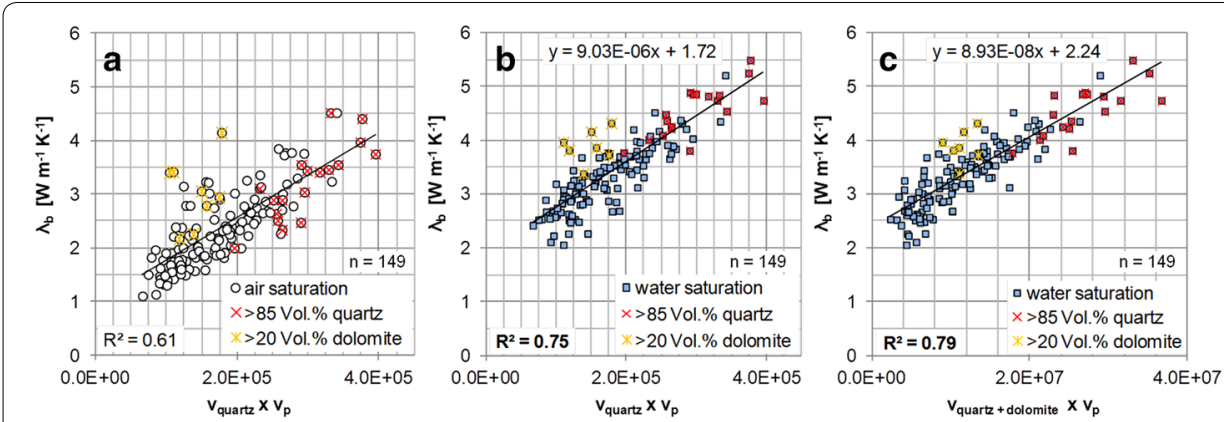

Fig. 11 Combination of mineralogical composition and $v_{p}$ values: cross-plots and resulting $R^{2}$ values of the product of total quartz volume fraction $\left(v_{\text {quartz }}\right)$ and $v_{p}$ versus a bulk thermal conductivity $\left(\lambda_{b}\right)$ of air-saturated sandstones and $\mathbf{b}$ bulk thermal conductivity $\left(\lambda_{b}\right)$ of water-saturated sandstones. $\mathbf{c}$ The product of the total quartz + dolomite volume fraction ( $v_{\text {quartz }}+$ dolomite) and $v_{p}$ plotted versus $\lambda_{b}$ achieves the best correlation of $R^{2}=0.79$ in the case of water-saturated sandstones. $\lambda_{\mathrm{b}}$ and $v_{\mathrm{p}}$ are measured parallel to bedding. Samples characterized by $>85$ vol.\% total quartz and samples with $>20$ vol.\% dolomite are highlighted 

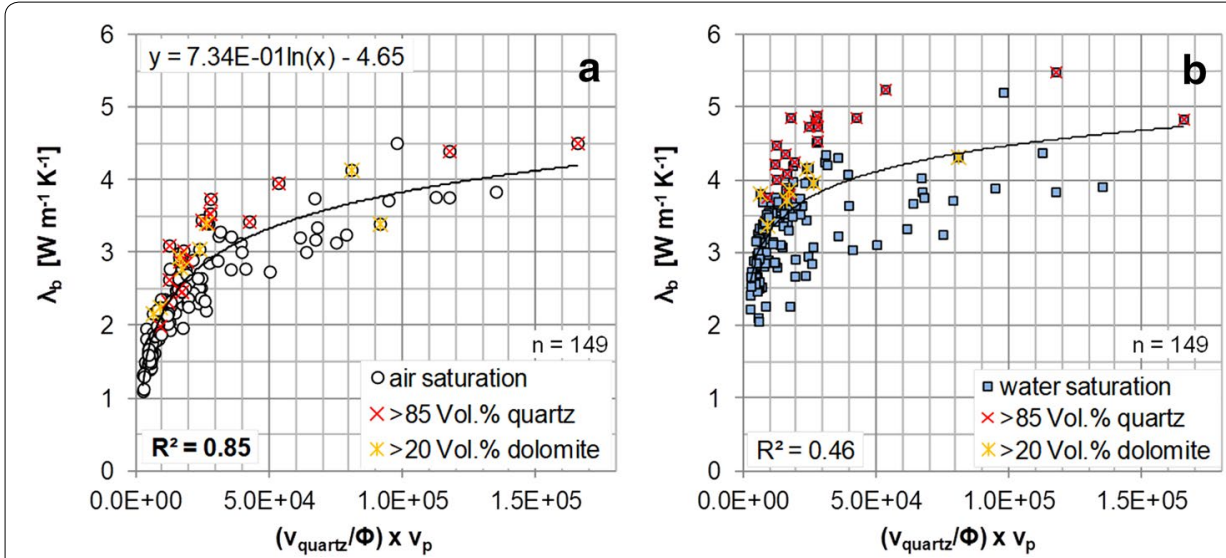

Fig. 12 Cross-plots of bulk thermal conductivity $\left(\lambda_{b}\right)$ versus the product of the ratio of quartz volume fraction $\left(v_{\text {quartz }}\right) / \Phi$ and $v_{p}$ for $\mathbf{a}$ air-saturated sandstone samples, $\mathbf{b}$ water-saturated sandstone samples. In case of air-saturated samples, the optimum correlation $R^{2}=0.85$ is achieved for plots bulk thermal conductivity $\left(\lambda_{b}\right)$ versus the product of the ratio of quartz volume fraction $\left(v_{\text {quartz }}\right) / \Phi$ and $v_{p} \cdot \lambda_{b}$ and $v_{p}$ are measured parallel bedding

\section{Conclusions}

The comparison of matrix thermal conductivities $\left(\lambda_{\mathrm{m}}\right)$ calculated from bulk thermal conductivity measurements of air- or water-saturated sandstones showed that the $\lambda_{\mathrm{m}}$ values of specific sandstones are significantly higher when measurements are derived from air-saturated samples compared to $\lambda_{\mathrm{m}}$ values from water-saturated measurements. The theoretical assumption that independently of the pore fluid, $\lambda_{\mathrm{m}}$ always remains constant is therefore incorrect. For both, water- and air-saturated sandstone samples tested, the mineral phases quartz, dolomite, kaolinite, and alkali feldspar as well as the porosity are identified as the main controlling factors of $\lambda_{\mathrm{m}}$. However, in the case of water saturation, the porosity exerts a significantly lower influence on $\lambda_{\mathrm{m}}$. The mineral phases quartz and dolomite exert a similarly strong influence in the case of both pore fluids being tested. In contrast, the alteration of alkali feldspar accompanied by formation of authigenic kaolinite in the pore space has different effects on $\lambda_{\mathrm{m}}$ dependent on the type of pore fluid. Due to an improvement in the grain contacts, the formation of kaolinite in the intergranular pore space leads to an increase of $\lambda_{\mathrm{m}}$, if the pores are saturated by air. In contrast, the precipitation of kaolinite has a significantly lower effect on the $\lambda_{\mathrm{m}}$ in case of water-saturated conditions because of the lower conductivity contrast between the pore fluid and the rock matrix.

The pore-fluid-dependent suitability tests of potential proxies for the estimation of the bulk rock thermal conductivity of sandstones proves that empirical models calibrated on air-saturated samples cannot be readily transferred to water-saturated conditions which are closer to the real in situ conditions in the subsurface. Individual rock parameters of the mineralogically heterogeneous sandstones investigated in this study do not provide suitable proxies for a valid estimation of their thermal conductivity. Depending on the type of pore fluid, the significance of the results of the regression analysis is highly variable.

Our results imply that rather different parameter combinations should be used to estimate the bulk thermal conductivity of air- or water-saturated sandstones. The easily 
measureable parameter $v_{\mathrm{p}}$ combined with other properties is regarded as a promising proxy for both pore fluid conditions tested: in combination with the $v_{\text {quartz }} / \Phi$ ratio for air-saturated sandstones and in combination with the $v_{\text {quartz }}+$ dolomite for water-saturated sandstones. Empirical $\lambda_{\mathrm{b}}$ models, which should be valid for water-saturated conditions in the subsurface, thus have to be calibrated on mineralogical composition data.

When calibrating empirical models for sandstones, it is also important to take anisotropy into account. The quantitative impact of anisotropy effects on measured values depends on the signal detection routine and the type of pore fluid present. In the case of air-saturated samples, anisotropy effects are more pronounced if the measurement signal has to pass through the entire sample diameter due to the measurement geometry $\left(v_{\mathrm{p}}\right)$. In contrast, the anisotropy effect is less pronouncedly expressed in the measurements if the signal transmitter and detector arrangement are not forcing the signal to pass through the entire sample (e.g., $\lambda_{\mathrm{b}}$ measurements with a thermal conductivity scanner).

The 707 Permo-Triassic sandstones samples investigated here cover a broad variability in mineralogical composition (e.g., total quartz volume fractions vary 26-97 vol.\%), thermal conductivity, $\Phi$, and $v_{\mathrm{p}}$. Therefore, the empirical models presented herein may also apply to sandstones of other stratigraphic origin.

\section{Abbreviations}

$\Phi$ : Porosity [\%]; $v_{\mathrm{p}}$ : Compressional wave velocity $\left[\mathrm{m} \mathrm{s}^{-1}\right] ; \lambda_{\mathrm{b}}$ : Bulk thermal conductivity $\left[\mathrm{W} \mathrm{m}^{-1} \mathrm{~K}^{-1}\right] ; \lambda_{\mathrm{m}}$ : Rock thermal conductivity of the rock matrix [ $\left.\mathrm{W} \mathrm{m}^{-1} \mathrm{~K}^{-1}\right] ; \lambda_{\mathrm{f}}$ :Thermal conductivity of the pore fluid $\left[\mathrm{W} \mathrm{m}^{-1} \mathrm{~K}^{-1}\right] ; v_{\text {quartz: }}$ Q Quartz volume fraction [vol.\%]; $v_{\text {dolomite: }}$ Dolomite volume fraction [vol.\%]; Anhy: Rock anhydrite; Cgl: Conglomerate; Clst: Claystone; Dol: Dolostone; Gyp: Gypsum rock; Ls: Limestone; mrlst: Marlstone; Sst: Sandstone.

\section{Acknowledgements}

We thank our collaborators of the Bayerisches Landesamt für Umwelt (LfU) for providing core material. We thank two anonymous reviewers for critical reading and commenting on the manuscript, which helped to improve the presentation of our research results.

\section{Authors' contributions}

MK carried out all the laboratory work for the measurement of the thermophysical data, the sampling of rock material, the collection and interpretation of the results, and the conception and design of the manuscript, tables, and figures. HS supervised the research and critically revised the manuscript. All authors read and approved the final manuscript.

\section{Funding}

This work was funded by grants from the Bavarian State Ministries StMUV "Exploration of the NE-Bavarian subsurface geology for the assessment of its geothermal potential" and StMBW "GAB-Geothermal Alliance Bavaria," which is gratefully acknowledged.

\section{Availability of data and materials}

All data generated or analyzed during this study are included in this published article.

Consent for publication

Not applicable.

Competing interests

The authors declare that they have no competing interests.

Received: 10 February 2019 Accepted: 26 April 2019

Published online: 13 May 2019

\section{References}

Albert K, Schulze M, Franz C, Koeningsdorf R, Zosseder K. Thermal conductivity estimation model considering the effect of water saturation explaining the heterogeneity of rock thermal conductivity. Geothermics. 2017;66:1-12. https:// doi.org/10.1016/j.geothermics.2016.11.006.

Anand J, Somerton WH, Gomaa E. Predicting thermal conductivities of formations from other known properties. Soc Petrol Eng J. 1973;13(5):267-72. https://doi.org/10.2118/4171-PA. 
Andrés C, Àlvarez R, Ordónez A. Estimation of thermal conductivity of rocks from their mineralogical composition (Asturian Coal Basin, NW Spain) for modelling purposes. Environ Earth Sci. 2016;75:266. https://doi.org/10.1007/s1266 5-015-5037-8.

Aurangzeb ZA, Gurmani SF, Maqsood A. Simultaneous measurement of thermal conductivity, thermal diffusivity and prediction of effective thermal conductivity of porous consolidated igneous rocks at room temperature. J Phys D Appl Phys. 2006;39:3876-81. https://doi.org/10.1088/0022-3727/39/17/025.

Augranzeb ZA, Maqsood A. Modeling of the effective thermal conductivity of consolidated porous media with different saturants: a test of gabbro rocks. Int J Thermophys. 2007;28(4):1371-86. https://doi.org/10.1007/s10765-007-0203-1.

Bär K. Untersuchung der tiefengeothermischen Potenziale von Hessen. PhD thesis, Technische Universität Darmstadt. 2012. https://tuprints.ulb.tu-darmstadt.de/3067/. Accessed 02 Feb 2019.

Berger K, Haunschild H, Schmidt-Kaler H, Wagner GH, Hüttner R, Zitzmann A. Geologische Übersichtskarte 1:200.000, Blatt CC 7126 Nürnberg. Hannover: BGR; 1977.

Birch F, Clark H. The thermal conductivity of rocks and its dependence upon temperature and composition. Am J Sci. 1940;238:529-58

Blackwell DD, Steele JL. Thermal conductivity of sedimentary rocks: measurement and significance. In: Naeser ND, McCulloh TH, editors. Thermal history of sedimentary basins. New York: Springer; 1989.

Brigaud F, Vasseur G. Mineralogy, porosity and fluid control on thermal conductivity of sedimentary rocks. Geophys J Int. 1989;98(3):525-42. https://doi.org/10.1111/j.1365-246X.1989.tb02287.x.

Brigaud F, Chapman DS, Le Douran S. Estimating thermal conductivity in sedimentary basins using lithologic data and geophysical well logs. Am Asso Petrol Geol Bull. 1990;74:1459-77.

Carson JK, Lovatt SJ, Tanner DJ, Cleland AC. An analysis of the influence of material structure on the effective thermal conductivity of theoretical porous materials using finite element simulation. Int J Refrig. 2003;26:873-80.

Chapman DS, Rybach L. Heat flow anomalies and their interpretation. J Geodyn. 1985;4(1-4):3-37.

Clauser C, Huenges E. Thermal conductivity of rocks and minerals: a handbook of physical constants. In: Ahrens, TJ, editor. Rock physics \& phase relations, AGU reference shelf, vol. 3. 1995. p. 105-26.

Clauser C, Koch A, Hartmann A, Jorand R, Mottaghy D, Pechnig R, Rath V, Wolf A. Erstellung statistisch abgesicherter thermischer und hydraulischer Gesteinseigenschaften für den flachen und tiefen Untergrund in Deutschland (Phase 1 - Westliche Molasse und nördlich angrenzendes Süddeutsches Schichtstufenland), Bericht, Applied Geophysics and Geothermal Energy, E.ON Energy Research Center, RWTH Aachen University. 2007. http://www.geophysica.de/ Forschung/Petrophysik_Abschluss_Phase_1.pdf. Accessed 02 Feb 2019.

Clauser C, Koch A, Jorand R, Vogt C, Arnold J, Mottaghy D, Pechnig R. Erstellung statistisch abgesicherter thermischer und hydraulischer Gesteinseigenschaften für den flachen und tiefen Untergrund in Deutschland (Phase 2 - Westliches Nordrhein-Westfalen und bayerisches Molassebecken), Bericht, Applied Geophysics and Geothermal Energy, E.ON Energy Research Center, RWTH Aachen University. 2009. http://www.geophysica.de/Forschung/Petrophysik_Absch luss_Phase_2.pdf. Accessed 02 Feb 2019.

Coté J, Konrad J-M. Assessment of structure effects on the thermal conductivity of two-phase porous geomaterials. Int J Heat Mass Transf. 2009;52:796-804. https://doi.org/10.1016/j.ijheatmasstransfer.2008.07.037.

Emmert U, Horstig VG, Stettner G, Zitzmann A. Geologische Übersichtskarte 1:200.000, Blatt CC6334 Bayreuth. Hannover: BGR; 1981.

Esteban L, Pimienta L, Sarout J, Delle Piane C, Haffen S, Geraud Y, Timms NE. Study cases of thermal conductivity prediction from p-wave velocity and porosity. Geothermics. 2015;53:255-69. https://doi.org/10.1016/j.geothermic s.2014.06.003.

Filomena CM, Stollhofen H, van Ojik K. High-resolution ultrasonic measurements as proxies to resolve clastic reservoir heterogeneity in a salt-cemented gas reservoir. AAPG Bull. 2012;96:1197-209.

Freudenberger W, Schwerd K. Erläuterungen zur geologischen Karte von Bayern 1: 500 000. München: Bayer Geol LA; 1996.

Freudenberger W, Zitzmann A. Geologische Übersichtskarte 1:200.000, Blatt CC6326 Bamberg. Hannover: BGR; 1994.

Fuchs S, Balling N. Improving the temperature prediction of subsurface thermal models by using high-quality data. Part 1: uncertainty analysis of the thermal conductivity parameterization. Geothermics. 2016;64:42-54. https://doi. org/10.1016/j.geothermics.2016.04.010.

Fuchs S, Föster A. Rock thermal conductivity of mesozoic geothermal aquifers in the Northeast German Basin. Chem Erde. 2010;70(S3):13-22. https://doi.org/10.1016/j.chemer.2010.05.010.

Fuchs S, Förster A. Well-log based prediction of thermal conductivity of sedimentary successions: a case study from the North German Basin. Geophys J Int. 2014;196:291-311.

Fuchs S, Schütz F, Förster HJ, Förster A. Evaluation of common mixing models for calculating bulk thermal conductivity of sedimentary rocks: correction charts and new conversion equations. Geothermics. 2013;47:40-52. https://doi. org/10.1016/j.geothermics.2013.02.002.

Gasior I, Przelaskowska A. Estimating thermal conductivity from core and well log data. Acta Geophys. 2014;62(4):785-801.

Gegenhuber N, Schön J. New approaches for the relationship between compressional wave velocity and thermal conductivity. J Appl Geophys. 2012;76:50-5. https://doi.org/10.1016/j.jappgeo.2011.10.005.

Gegenhuber N, Kienler M. Improved petrographic-coded model and its evaluation to determine a thermal conductivity log. Acta Geophys. 2017;65:103-18. https://doi.org/10.1007/s11600-017-0010-4.

Goss R, Combs J, Timur A. Prediction of thermal conductivity in rocks from other physical parameters and from standard geophysical well logs. In: SPWLA 16th annual logging symposium, June 4-7. 1975.

Goutorbe B, Lucazeau F, Bonneville A. Using neural networks to predict thermal conductivity from geophysical well logs. Geophys J Int. 2006;166(1):115-25.

Hartmann A, Rath V, Clauser C. Thermal conductivity from core and well log data. Int J Rock Mech Min Sci. 2005:42(78):1042-55. https://doi.org/10.1016/j.jijmms.2005.05.015.

Horai K. Thermal conductivity of rock-forming minerals. J Geophys Res. 1971;76(5):1278-308. https://doi.org/10.1029/ JB076i005p01278. 
Horai K, Baldridge S. Thermal conductivity of nineteen igneous rocks, II Estimation of the thermal conductivity of rock from the mineral and chemical compositions. Phys Earth Planet Interiors. 1972;5:157-66. https://doi. org/10.1016/0031-9201(72)90085-4.

Horseman ST, McEwen TJ. Thermal constraints on disposal of heat-emitting waste in argillaceous rocks. Eng Geol. 1996;41(1-4):5-16.

Jorand R, Fehr A, Koch A, Clauser C. Study of the variation of thermal conductivity with water saturation using nuclear magnetic resonance. J Geophys Res. 2011;116:B08208. https://doi.org/10.1029/2010JB007734.

Jorand R, Clauser C, Marquart G, Pechnig R. Statistically reliable petrophysical properties of potential reservoir rocks for geothermal energy use and their relation to lithostratigraphy and rock composition: the NE Rhenish Massif and the Lower Rhine Embayment (Germany). Geothermics. 2015;53:413-28.

Kappelmeyer O, Hänel R. Geothermics with special reference to application, series 1, no 4. Geoexploration Monograph, Berlin. 1974

Littke R, Bayer U, Gajewski D, Nelskamp S, editors. Dynamics of complex intracontinental basins: the Central European Basin System. Berlin: Springer; 2008.

Maqsood A, Kamran K, Gul IH. Prediction of thermal conductivity of granite rocks from porosity and density data at normal temperature and pressure: in situ thermal conductivity measurements. J Phys D Appl Phys. 2004;37:3396-401. https://doi.org/10.1088/0022-3727/37/24/007.

Meyer R, Mielke H, Schmidt-Kaler H, Unger HJ, Zitzmann A. Geologische Übersichtskarte 1:200.000, Blatt CC7134 Regensburg. Hannover: BGR; 1994.

Özkahraman H, Selver R, Işık EC. Determination of the thermal conductivity of rock from P-wave velocity. Int J Rock Mech Min Sci. 2004;41:703-8. https://doi.org/10.1016/j.jirmms.2004.01.002.

Pimienta L, Sarout J, Esteban L, Delle Piane C. Predicting of rocks thermal conductivity from elastic wave velocities, mineralogy and microstructure. Geophys J Int. 2014;197:860-74. https://doi.org/10.1093/gji/ggu034.

Popov YA, Pribnow DFC, Sass JH, Williams CF, Burkhardt H. Characterization of rock thermal conductivity by high-resolution optical scanning. Geothermics. 1999;28:253-76. https://doi.org/10.1016/S0375-6505(99)00007-3.

Pribnow D. Ein Vergleich von Bestimmungsmethoden der Wärmeleitfähigkeit unter Berücksichtigung von Gesteinsgefügen und Anisotropie Ausgabe 75 von Fortschritt-Berichte VDI/19: Wärmetechnik, Kältetechnik, Verein Deutscher Ingenieure. 1994.

R Development Core Team. R: a language and environment for statistical computing. Vienna: R Foundation for Statistical Computing. ISBN 3-900051-07-0. 2008. http://www.R-project.org. Accessed 12 Dec 2018.

Radzinski KH, Kästner H, Seidel G, Wiefel H, Berger H-J, Zitzmann A. Geologische Übersichtskarte 1:200.000, Blatt CC5534 Zwickau. Hannover: BGR; 1999.

Robertson EC. Thermal properties of rocks, U.S.G.S. Open file report 88-441, US Geol Survey, Reston. 1988. https://doi. org/10.3133/ofr88441.

Schön JH. Physical properties of rocks. Fundamentals and principles of petrophysics. Developments in petroleum science, vol. 65. Amsterdam: Elsevier; 2015.

Seidel G, Kästner H, Wiefel H, Zitzmann A. Geologische Übersichtskarte 1:200.000, Blatt CC5526 Erfurt. Hannover: BGR; 1998.

Somerton WH. Thermal properties and temperature-related behaviour of rock/fluid systems. Developments in petroleum science, vol. 37. New York: Elsevier; 1992.

STC (German Stratigraphic Commission, ed.; editing, coordination and layout: Menning, M. and Hendrich, A.) Stratigraphic Table of Germany 2016 Potsdam, GeoForschungsZentrum. 2016. http://gfzpublic.gfz-potsdam.de/pubma n/faces/viewltemFullPage.jsp;jsessionid=2BED190CAEDCB15D632FE0F610F5F4CF?itemld=escidoc\%3A252 4907\%3A2\&view=EXPORT. Accessed 11 Oct 2018.

Sugawara A, Yoshizawa Y. An investigation on the thermal conductivity of porous materials and its application to porous rock. Aust J Phys. 1961;14(4):469-80. https://doi.org/10.1071/PH610469.

Sun Q, Chen S, Gao Q, Zhang W, Geng J, Zhang Y. Analyses of the factors influencing sandstone thermal conductivity. Acta Geodyn Geomater. 2017;14(2):186.

Walsh J, Decker ER. Effect of pressure and saturation fluid on the thermal conductivity of compact rock. J Geophys Res. 1966;71(12):3053-61. https://doi.org/10.1029/JZ071i012p03053.

Woodside W, Messmer JH. Thermal conductivity of porous media. I. Unconsolidated sands. J Appl Phys. 1961a;32(9):1688-99. https://doi.org/10.1063/1.1728419.

Woodside W, Messmer JH. Thermal conductivity of porous media. II. Consolidated rocks. J Appl Phys. 1961 b;32(9):1699706. https://doi.org/10.1063/1.1728420.

Wyllie MRJ, Gregory AR, Gardner IW. Elastic wave velocities in heterogeneous and porous media. Geophysics. 1956;21(1):41-70. https://doi.org/10.1190/1.1438217.

Xu Z, Reed, CB, Parker, R, Graves R. Laser spallation of rocks for oil well drilling. In: Proceedings of the 23rd international congress on applications of lasers and electro-optics. 2004. p. 1-6.

Zimmerman RW. Thermal conductivity of fluid-saturated rocks. J Petrol Sci Eng. 1989;3(3):219-27.

Zinszner B, Pellerin F-M. A Geoscientist's guide to petrophysics. IFP Publications, Éd. Technip; 2007.

\section{Publisher's Note}

Springer Nature remains neutral with regard to jurisdictional claims in published maps and institutional affiliations. 